\title{
INFLUÊNCIA DE PAREDES VERDES NO DESEMPENHO TÉRMICO DE HABITAÇÕES SOCIAIS
}

\section{INFLUENCE OF GREEN WALLS ON THE THERMAL PERFORMANCE OF SOCIAL HOUSING}

\author{
Luana Resende de Sousa ${ }^{1}$ \\ Universidade Federal de Ouro Preto, Ouro Preto, MG, Brasil, luanasousar@gmail.com \\ Henor Artur de Souza ${ }^{2}$ \\ Universidade Federal de Ouro Preto, Ouro Preto, MG, Brasil, henorster@gmail.com \\ Adriano Pinto Gomes ${ }^{3}$ \\ Instituto Federal de Minas Gerais, Ouro Preto, MG, Brasil, adriano.gomes@ifmg.edu.br
}

\begin{abstract}
Resumo
A utilização da vegetação como elemento de fachada ainda compreende uma prática bastante incipiente, mas tem se popularizado devido à promessa de melhoria no desempenho térmico das edificações, além de representar uma alternativa de ampliação da biodiversidade no ambiente urbano. Neste trabalho investiga-se a influência das paredes verdes, no contexto climático brasileiro, sobre o desempenho térmico de edifícios habitacionais de interesse social. Como metodologia, utiliza-se a simulação do comportamento termoenergético de um edifício habitacional multifamiliar, por meio do programa EnergyPlus, incluindo-se o modelo HAMT que leva em conta o processo de transferência de umidade através da envoltória, para três zonas bioclimáticas previstas na norma NBR 15.220-2005, clima extremo para inverno (ZB1), clima extremo de verão (ZB8) e para um clima considerado como intermediário (ZB3). Os resultados obtidos demonstram uma diferença na temperatura interna dos ambientes, decorrente dos dois arranjos de fachada analisados: com e sem vegetação. $O$ uso da parede verde proporcionou uma redução na temperatura interna de até $2,8{ }^{\circ} \mathrm{C}$ no verão e um aumento de até $1,4{ }^{\circ} \mathrm{C}$ no inverno. Observa-se que a vegetação na fachada ajudou a manter a temperatura interna mais baixa durante o dia e amena durante a noite. Logo, as paredes verdes podem representar uma solução sustentável e de baixo custo a ser implantada às edificações, visando melhorar seu desempenho térmico.
\end{abstract}

Palavras-chave: Paredes verdes. Simulação computacional. Calor e umidade. Desempenho térmico. EnergyPlus.

\begin{abstract}
Although the benefits of vegetation are widely known, its use as a facade element remains a very incipient practice. This strategy has become popular due to the promise of improvement on the thermal performance of buildings, in addition to representing an alternative for expanding biodiversity in the urban environment. This paper investigates the influence of green walls, within the Brazilian climate context, on the thermal performance of social housing buildings. The methodology consists of the simulation of the thermal and energy behavior of a multifamily housing building. The simulation is performed with the EnergyPlus ${ }^{\circledR}$ program, including the HAMT model, that takes into account the moisture transfer process through the envelope for three bioclimatic zones provided by the Brazilian standard NBR 15520-2005: extreme winter climate (ZB1), extreme summer climate (ZB8), and a climate considered as the intermediary (ZB3). The results obtained demonstrate a difference in the environments' indoor temperature caused by the two facade arrangements: with and without vegetation. The green wall's use provided a reduction in the indoor temperature of up to $2.8^{\circ} \mathrm{C}$ in summer and an increase of up to $1.4^{\circ} \mathrm{C}$ in winter. The facade's vegetation worked as a layer of thermal insulation, helping to keep the indoor temperature lower during the day and mild during the night. Therefore, green walls can represent a sustainable and low-cost solution to be implemented in buildings, aiming to improve their thermal performance.
\end{abstract}

Keywords: Green Walls. Computer Simulation. Heat and Humidity. Thermal performance. EnergyPlus.

How to cite this article:

SOUSA, Luana Resende de; SOUZA, Henor Artur de; GOMES, Adriano Pinto. Influência de paredes verdes no desempenho térmico de habitações sociais. PARC Pesquisa em Arquitetura e Construção, Campinas, SP, v. 11, p. e020029, 2019. DOI: http://dx.doi.org/10.20396/parc.v11i0.8658167 


\section{Introdução}

O crescimento acelerado e desordenado das cidades é responsável por gerar espaços urbanos com adensamentos desproporcionais e infraestrutura ineficiente. Por isso, as grandes cidades brasileiras, assim como aquelas de países latino-americanos, enfrentam diversos problemas ocasionados pelos impactos ambientais negativos da urbanização e da vivência em alta densidade, como o aquecimento atmosférico, a impermeabilização do solo, a carência de áreas verdes, o aumento da poluição do ar e a formação de ilhas de calor. Nesse sentido, estudos sobre o ambiente urbano ressaltam a necessidade de se requalificar os espaços, a fim de garantir bem-estar, qualidade de vida e conforto ambiental para a população (CAETANO, 2014; SCHERER, 2014; MORELLI, 2016).

No que se refere às edificações, desde a publicação da norma de desempenho NBR 15.575 em 2013, os conceitos de desempenho e conforto térmico receberam maior destaque em âmbito nacional, sendo responsáveis por elevar a responsabilidade do ato de projetar e fomentar o desenvolvimento de estratégias e tecnologias capazes de auxiliar nas tomadas de decisão projetual. Desta forma, as exigências atuais apontam para projetos de edificações que visam proporcionar condições mínimas de conforto ao usuário, além de assegurar-lhes eficiência energética satisfatória. Nesse contexto, a avaliação da edificação com o auxílio de ferramentas de simulação computacional pode promover um processo de projeto mais eficiente, pois permite prever o comportamento térmico do edifício sob diferentes condições climáticas, antevendo e predizendo possíveis deficiências que podem ser contornadas e reavaliadas ainda na fase de planejamento (BRíGITTE, 2013).

Diante disso e frente ao esgotamento de recursos naturais, alternativas sustentáveis de construção são cada vez mais valorizadas. A arquitetura possui um papel muito importante nesse sentido pois, por meio de decisões projetuais adequadas e da correta utilização de recursos naturais, pode propiciar não somente melhorias ambientais ao microclima, como também oferecer edifícios salubres, confortáveis e energeticamente eficientes a seus usuários. Da mesma forma, a vegetação, embora pouco explorada, é um elemento natural capaz de proporcionar inúmeros benefícios às características térmicas de um local. Para Garrido (2012), a utilização adequada da vegetação nas edificações representa uma das mais importantes ações a serem realizadas na tentativa de se assegurar melhores condições ambientais ao edifício. Cantuária (1995) também defende o uso da vegetação na criação de ambientes salubres, principalmente por se tratar de um sistema de fácil aplicação, que não requer nenhuma tecnologia avançada e pode ser aplicado em todo o mundo.

Sabe-se que os sistemas de fechamento de um edifício funcionam como um elemento de conexão entre o exterior e o ambiente construído, exercendo grande influência em seu desempenho térmico. Diante disso, a utilização da vegetação na envoltória da edificação pode, além de proteger a construção, oferecer benefícios ao seu desempenho térmico e melhorias nos níveis de umidade do ar, por meio da redução da incidência solar e do processo de evapotranspiração das plantas, respectivamente. Além disso, se apresenta como uma solução conveniente de inserção de áreas verdes na cidade (DUNNETT; KINGSBURY, 2004; VALESAN, 2009).

Assim, seguindo a tendência de se agregar a vegetação às fachadas das edificações, neste trabalho explora-se a tecnologia das paredes verdes no contexto climático brasileiro, com enfoque no desempenho térmico de edifícios habitacionais de interesse social. Estas habitações correspondem, muitas vezes, a projetos padronizados construídos em larga escala e repetidos em diversas localidades do país, sem considerar critérios importantes como insolação e ventilação natural, causando prejuízos na 
diversidade arquitetônica e na qualidade das edificações. Portanto, por meio da utilização de uma ferramenta de simulação computacional, o programa EnergyPlus, e incluindo o modelo Combined Heat and Moisture Tranfer Model (HAMT), que leva em consideração a transferência de umidade na envoltória, avalia-se o desempenho térmico de edificações que utilizam paredes verdes, para três condições climáticas: uma região com clima extremo de inverno, uma região com clima extremo de verão e uma região com clima considerado como intermediário.

\section{Sistemas de vegetação na envoltória da edificação}

Nos estudos sobre o revestimento vegetal nas construções, pesquisas sobre telhados verdes são bem mais frequentes, em decorrência da maior utilização e difusão desta técnica, enquanto os jardins verticais compreendem um sistema com pesquisa ainda incipiente (COSTA, 2011; MATHEUS et al., 2016; DAHANAYAKE; CHOW, 2018). Tal tema faz-se relevante, uma vez que estudos apontam que o uso de vegetação nas fachadas constitui uma solução vantajosa. Em primeiro lugar, devido ao perfil verticalizado dos centros urbanos, onde a área de superfícies verticais é consideravelmente maior que a área de coberturas, resultando em uma maior disponibilidade de área vertical para implantação de vegetação (KÖHLER, 2008; CAETANO, 2014). Em segundo lugar, por permitir a visualização da vegetação pelas pessoas, oferecendo conforto visual e embelezamento urbano (CAETANO, 2014).

Dahanayake e Chow (2018) apontam que a cobertura vegetal nas fachadas promove maiores benefícios térmicos para edifícios de vários pavimentos, em comparação às coberturas verdes pois, enquanto o jardim vertical influencia no desempenho térmico de todos os andares, o telhado verde tem influência significativa apenas no desempenho dos pavimentos mais altos. Ao se considerar edifícios de apenas um pavimento, no entanto, o telhado verde contribui para uma maior redução na carga de resfriamento, em comparação aos jardins verticais. Além de receber maior incidência solar, o telhado verde geralmente apresenta uma área de cobertura superior à área de fachada (DAHANAYAKE; CHOW, 2018).

As vantagens dos jardins verticais têm despertado o interesse de pesquisadores ao redor do mundo, tendo em vista realizar uma caracterização mais precisa de suas configurações sob diferentes condições climáticas, em especial no que diz respeito ao seu potencial de condicionamento térmico passivo em ambientes construídos (KÖHLER, 2008; COSTA, 2011).

\section{Jardins Verticais: Paredes Vivas e/ou Paredes Verdes}

Em geral, a cobertura de fachadas por espécies vegetais apresenta diferentes nomenclaturas, que compreendem termos como: jardins verticais, paredes verdes, paredes vivas, sistemas de vegetação vertical, biofachadas, peles verdes, cortinas verdes, superfícies vegetadas, entre outros (KÖHLER, 2008; VALESAN, 2009; PERINI et al., 2011; PÉREZ et al., 2011; SCHERER, 2014; MANSO; CASTRO-GOMES, 2015; BARBOSA; FONTES, 2016; MUÑOZ et al., 2019). Determinados termos se referem a modelos específicos, que diferem entre si em virtude de suas características de construção (MANSO; CASTRO-GOMES, 2015; BARBOSA; FONTES, 2016; MUÑOZ et al., 2019).

Os termos jardim vertical, sistema de vegetação vertical e superfície vegetada abrangem todos os sistemas de crescimento e desenvolvimento da vegetação em uma superfície delimitada verticalmente. Como categoria mais abrangente, os jardins verticais podem ainda ser divididos em duas tipologias principais: paredes verdes e paredes vivas, a depender da forma de implementação, da dificuldade de execução e da necessidade de manutenção (PERINI et al., 2011; KONTOLEON; EUMORFOPOULOU, 
2010; MANSO; CASTRO-GOMES, 2015; BARBOSA; FONTES, 2016; SCHERER; ALVES; REDIN, 2018) (Figura 1).

Figura 1 - Classificação dos sistemas de jardim vertical

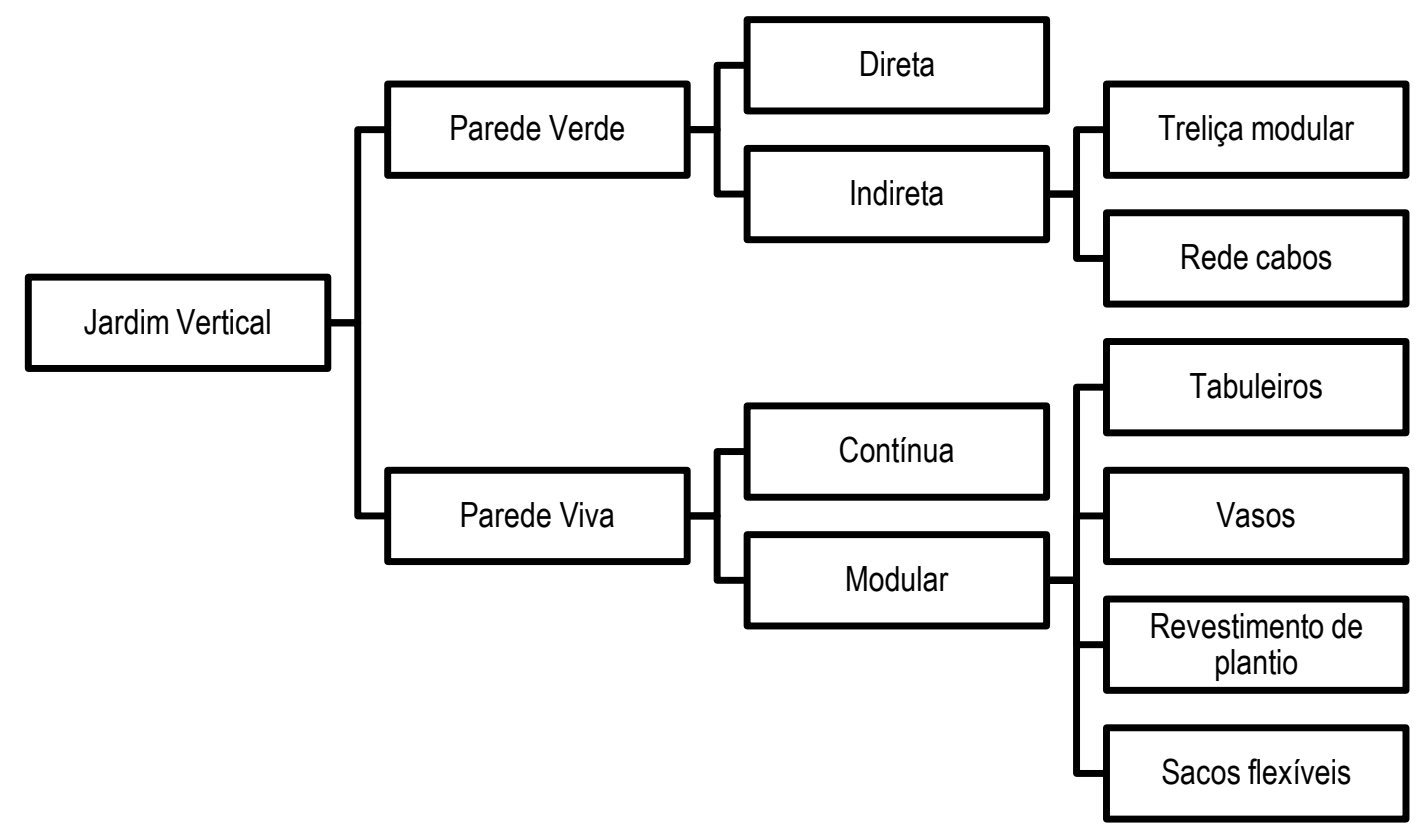

Fonte: Adaptado de Manso e Castro-Gomes (2015).

\section{Paredes Vivas}

As paredes vivas compõem um sistema intensivo de construção e manutenção complexa, que agrega o meio de crescimento diretamente à envoltória das edificações, liberando as plantas da dependência do solo (KÖHLER, 2008; VALESAN, 2009; BARBOSA; FONTES, 2016; MATHEUS et al., 2016). Classificam-se em contínuas ou modulares, a depender da forma de acondicionamento das espécies vegetais (MANSO; CASTRO-GOMES, 2015; BARBOSA; FONTES, 2016).

Essa configuração corresponde a modelos mais recentes, produzidos com maior incorporação tecnológica e que requerem o uso de sistemas de apoio à nutrição e hidratação. Tais requisitos, aliados à necessidade de montagem especializada e manutenção do sistema, acabam por encarecer seu custo inicial (OTTELÉ et al., 2011; CAETANO, 2014; MATHEUS et al., 2016). Embora apresente esse aspecto inconveniente, as paredes vivas proporcionam algumas vantagens sobre os demais sistemas, como: maior poder de isolamento térmico devido às diversas camadas; prevenção de danos à envoltória, devido à independência da alvenaria; efeito visual imediato; possibilidade de uso de uma maior variedade de plantas; facilidade de instalação e substituição, por sua característica modular; possibilidade de criação de muros decorativos e de expansão, viabilizando seu uso em prédios (CAETANO, 2014; MATHEUS et al., 2016).

O Brasil ainda apresenta um mercado muito pequeno para a implantação da parede viva, principalmente pela falta de informação técnica e científica dos profissionais da construção civil, pela carência de mão de obra especializada para instalação e manutenção do sistema, além do alto valor de investimento (MORELLI, 2016).

\section{Paredes Verdes}

A parede verde refere-se ao revestimento de alvenarias e demais estruturas verticais pelo plantio de vegetação autoaderente diretamente em sua superfície ou com a 
utilização de suportes. De maneira geral, as paredes verdes constituem um sistema extensivo, de fácil construção e manutenção, em que as raízes vegetais encontram-se na base da estrutura, em contato direto com o solo ou com algum outro tipo de substrato, necessitando de poucos cuidados com relação à nutrição e irrigação (DUNNETT; KINGSBURY, 2004; VALESAN, 2009; SCHERER; ALVES; REDIN, 2018). Em vista disso, as paredes verdes não requerem um alto valor de investimento (KÖHLER, 2008; VALESAN, 2009). Esta técnica, no entanto, apresenta algumas limitações práticas relacionadas a fatores como: (1) alcance vertical, que pode variar de acordo com a espécie de trepadeira utilizada, possuindo um limite de altura de cerca de $20 \mathrm{~m}$, em geral (KÖHLER, 2008; BARBOSA; FONTES, 2016); (2) crescimento lento; e (3) problemas com infiltração e/ou danos físicos ao edifício, caso a parede não esteja adequadamente protegida (CAETANO, 2014; SCHERER; ALVES; REDIN, 2018).

As paredes verdes podem assumir duas classificações: Parede Verde Direta, quando a vegetação possui capacidade autônoma de fixação, utilizando a própria fachada da edificação como suporte; ou Parede Verde Indireta, quando estruturas especialmente projetadas dão suporte à vegetação e guiam seu crescimento (KÖHLER, 2008; VALESAN; FREDRIZZI; SATTLER, 2010; PERINI et al., 2013; HUNTER et al., 2014; SCHERER, 2014; BARBOSA; FONTES, 2016; BESIR; CUCE, 2018; MUÑHOZ et al., 2019). Em ambos os casos, a vegetação pode ser plantada diretamente no solo ou em jardineiras. Neste último caso, no entanto, são necessários maiores cuidados com relação à nutrição e irrigação das espécies (KÖHLER, 2008; BARBOSA; FONTES, 2016; SCHERER; ALVES; REDIN, 2018; MUÑHOZ et al., 2019) (Figura 2).

Figura 2 - Classificação das paredes verdes

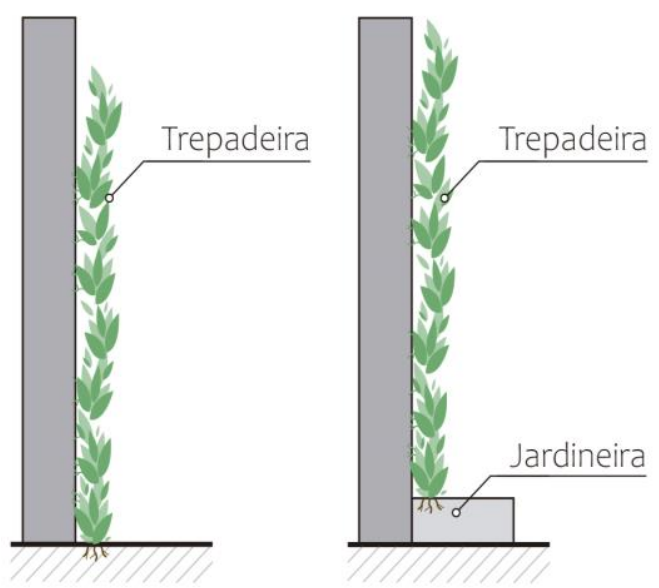

Fachada Verde Direta
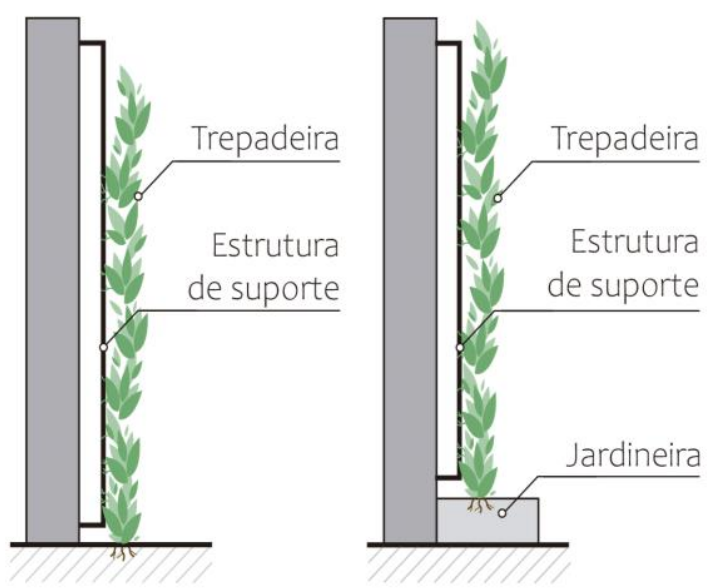

Fachada Verde Indireta

Fonte: os autores.

As Paredes Verdes Diretas correspondem à forma mais natural e tradicional de jardim vertical, que se caracterizam pela utilização de espécies trepadeiras autoaderentes, formando um revestimento que remete a uma pele verde (KÖHLER, 2008; VALESAN, 2009; SCHERER, 2014). As Paredes Verdes Indiretas, também denominadas cortinas verdes, consistem em sistemas onde se faz necessária a instalação de uma estrutura suporte, ao longo da qual a vegetação se desenvolve, podendo variar quanto ao material utilizado e quanto à sua disposição. Segundo Scherer (2014), a principal particularidade desta tipologia de jardim vertical é a possibilidade de sobreposição da vegetação às aberturas ou regiões envidraçadas da edificação, que a permite atuar como elemento arquitetônico de controle solar, além de proporcionar um surpreendente efeito visual de luz e sombra aos recintos arquitetônicos. 
Atualmente, o uso da vegetação integrada às fachadas das edificações é considerado uma técnica coerente com os princípios de sustentabilidade e eficiência energética. Grandes centros urbanos, tais como Londres na Inglaterra, Seattle nos Estados Unidos e Toronto no Canadá, implantaram políticas de incentivo ao uso de jardins verticais, telhados verdes e demais formas de vegetação, como forma de aumentar as superfícies vegetadas nas áreas urbanas e no ambiente construído (SCHERER, 2014; MORELLI, 2016). No Brasil, a cidade de São Paulo, com o intuito de ampliar suas áreas verdes e contribuir com o aumento da qualidade de vida urbana, tomou medidas semelhantes, como a conversão da compensação ambiental em jardins verticais, a partir do Decreto 55.994 de março de 2015 (SÃO PAULO, 2015; BARBOSA; FONTES 2016).

Contudo, estudos científicos que demonstram os benefícios e cuidados a serem tomados na aplicação desses sistemas ainda são relativamente recentes (KÖHLER, 2008; SCHERER, 2014; MONTANARI; LABAKI, 2017; MUÑOZ et al., 2019). Com base na pesquisa de Muñoz et al. (2019), que realizaram uma revisão da literatura acerca do potencial amenizador térmico de paredes verdes, é possível perceber a atualidade do assunto, já que a publicação não cita trabalhos anteriores ao ano de 2008. Observa-se também que as publicações se referem principalmente a regiões da Ásia, Europa e Oriente Médio, o que destaca a necessidade de pesquisas semelhantes em climas brasileiros (MONTANARI; LABAKI, 2017; MUÑOZ et al., 2019).

Pesquisas experimentais realizadas por meio de medições in loco compreendem grande parte dos estudos sobre o tema. Como exemplo, Eumorfopoulou e Kontoleon (2009) compararam as temperaturas superficiais de um edifício com paredes verdes localizado na Grécia, encontrando uma redução média de $5,7^{\circ} \mathrm{C}$ na temperatura superficial externa da parede coberta por vegetação em relação à parede controle, sem vegetação. Em Singapura, Wong et al. (2010) avaliaram o desempenho térmico de diversas tipologias de jardins verticais, encontrando reduções de até $4,4{ }^{\circ} \mathrm{C}$ na temperatura superficial do muro com parede verde indireta. Em concordância com estes resultados, Pérez et al. (2011) encontraram reduções médias de $5,5^{\circ} \mathrm{C}$ na temperatura superficial de um muro revestido por trepadeiras em treliças localizado na Espanha. Koyama et al. (2013) alcançaram uma redução máxima de $7,9^{\circ} \mathrm{C}$ na temperatura superficial externa de uma parede revestida pela espécie Canavalia gladiata, se comparada à superfície sem vegetação, em experimento realizado no Japão. Yang et al. (2018) desenvolveram uma pesquisa de campo sobre o desempenho térmico de um edifício administrativo em um campus universitário localizado em Xangai, China. Os resultados mostraram o potencial das paredes verdes na melhoria do desempenho térmico e na economia de energia para os ambientes contíguos às fachadas analisadas (norte e sul), apresentando redução nas temperaturas superficiais e nas temperaturas do ar interno de até $8,7{ }^{\circ} \mathrm{C}$ e $2,5^{\circ} \mathrm{C}$, respectivamente.

Alguns estudos utilizam modelos matemáticos para simular a resposta térmica de edifícios com paredes verdes. É o caso do trabalho de Cuce (2016) que, a partir de uma investigação numérica e experimental, comprovou a capacidade de regulação térmica de sistemas de paredes verdes diretas em Nottingham, Inglaterra. Os resultados demonstraram que as paredes com vegetação podem sofrer reduções de temperatura maiores que $6{ }^{\circ} \mathrm{C}$ sob condições de céu ensolarado, enquanto em condições de céu nublado chegou-se a reduções de aproximadamente $4{ }^{\circ} \mathrm{C}$. Em Hong Kong, Dahanayake e Chow (2018) compararam os benefícios de paredes e coberturas verdes na redução da carga de resfriamento de um edifício utilizando o programa EnergyPlus. Os resultados comprovaram que tanto as paredes como os telhados verdes foram capazes de proteger a envoltória do edifício, mas observou-se a maior contribuição das paredes verdes na redução da temperatura interna em edifícios de vários pavimentos. 
No Brasil, Valesan (2009) analisou a presença de vegetação trepadeira na fachada de um edifício residencial localizado na cidade de Porto Alegre, RS, tendo em vista a criação de um registro sobre a utilização desta técnica, seus principais problemas e potencialidades, por meio da aplicação de um questionário aos moradores. Obteve-se $73 \%$ de aprovação para o uso do sistema, sendo destacados elementos positivos como beleza, contato com a natureza e bem-estar. A partir dos depoimentos, percebeu-se também que o sucesso da aplicação das paredes verdes estava diretamente relacionado à qualidade e frequência correta de manutenção.

Em experimento realizado na cidade de Campinas, SP, Morelli e Labaki (2013) avaliaram o desempenho térmico de paredes verdes aplicadas em três células teste de construção idêntica, que se diferenciavam pela presença de trepadeira na fachada e por sua forma de fixação (direta ou indireta). Observou-se que as paredes verdes apresentaram um efeito minimizador no ganho de calor, contribuindo para a umidificação do ar e amenizando os extremos de temperatura.

Matheus et al. (2016), por meio de medições in loco realizadas nas cidades de Campinas e Atibaia, SP, avaliaram o desempenho térmico de edificações com diferentes revestimentos vegetais para proteção da envoltória, sendo eles: cobertura verde, parede viva e parede verde. Os resultados mostraram que os três sistemas atuaram de forma positiva sobre a diminuição do ganho de calor da construção. As paredes verdes contribuíram com a diminuição de até $2{ }^{\circ} \mathrm{C}$ na temperatura interna da edificação.

De modo geral, melhorias no desempenho térmico das edificações são proporcionadas pelas paredes verdes por meio de quatro mecanismos, sendo eles: (1) sombreamento, que bloqueia a incidência direta da radiação solar e, consequentemente, auxilia na redução da entrada de calor na edificação; (2) isolamento térmico, de modo que a vegetação e a camada de ar existente entre a parede e a folhagem são responsáveis por aumentarem a resistência térmica da envoltória; (3) barreira ao vento, que bloqueia parcialmente os ventos e diminui as trocas térmicas por convecção e infiltração do ar para o interior das edificações; e (4) resfriamento evaporativo, processo de evapotranspiração das plantas, que consome calor sensível e promove o aumento da umidade no entorno (WONG et al., 2010; PEREZ et al., 2011; HUNTER et al., 2014; SUSOROVA, 2015; MORELLI, 2016; WONG; BALDWIN, 2016; BESIR; CUCE, 2018; MUÑOZ et al., 2019).

\section{Método}

Para o desenvolvimento deste estudo são realizadas simulações computacionais do comportamento termoenergético de um edifício habitacional multifamiliar, por meio do programa EnergyPlus (versão 9.0.1), incluindo também o modelo HAMT, que leva em conta a transferência de umidade através da envoltória. Os resultados obtidos na simulação computacional são então comparados, com o intuito de se averiguar a influência das paredes verdes na temperatura interna da edificação. A simulação computacional é realizada para verificar a influência de estratégias de projeto que visam melhorar o desempenho térmico das edificações, de modo a proporcionar conforto térmico adequado aos usuários. Neste caso, verifica-se a utilização da vegetação como elemento de fachada em duas tipologias de parede verde: direta e indireta.

\section{Estudo de caso}

O edifício utilizado para a realização das simulações computacionais corresponde a um projeto padrão de interesse social multifamiliar, inserido no programa do Governo Federal Minha Casa Minha Vida - MCMV (BRASIL, 2009). Baseado nos parâmetros do 
MCMV, o modelo proposto para a análise trata-se de um edifício de quatro pavimentos, com planta do tipo " $\mathrm{H}$ ", comumente utilizada neste tipo de habitação. Os quatro andares seguem o mesmo "pavimento-tipo", apresentando quatro apartamentos por andar (Figura 3).

Figura 3 - Planta baixa da edificação analisada

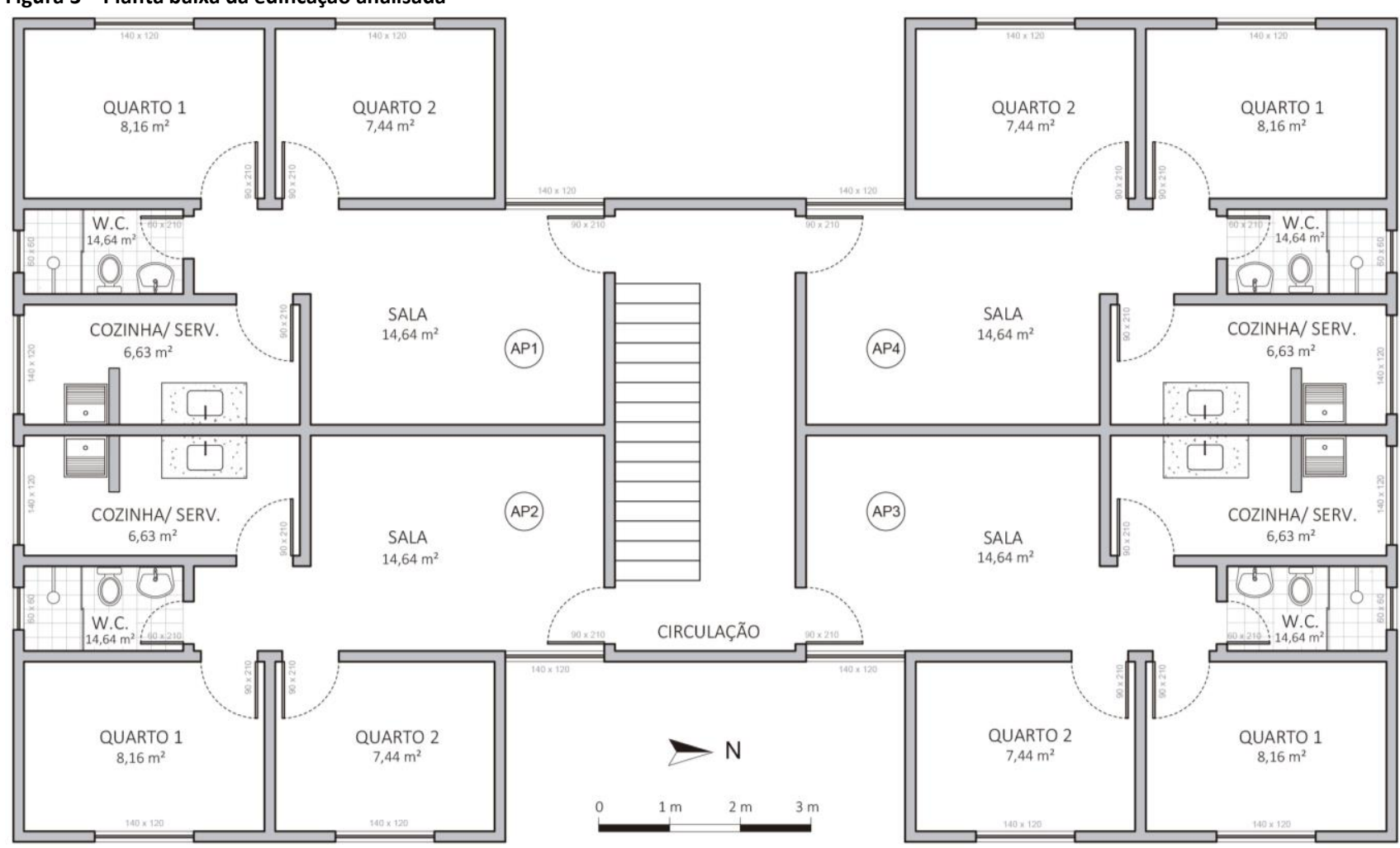

Fonte: os autores.

Cada unidade habitacional apresenta dois dormitórios, sala, cozinha integrada à área de serviço e banheiro social, compondo uma área total de 39,57 $\mathrm{m}^{2}$. Na Tabela 1 apresentase o respectivo quadro de áreas.

Tabela 1 - Quadro de áreas da unidade habitacional

\begin{tabular}{ccccc}
\hline Zona Térmica & Ambiente & Dimensões & Pé-direito & Área do Piso \\
\hline 1 & Quarto 1 & $3,40 \mathrm{~m} \times 2,40 \mathrm{~m}$ & $2,40 \mathrm{~m}$ & $8,16 \mathrm{~m}^{2}$ \\
\hline 2 & Banheiro Social & $1,20 \mathrm{~m} \times 2,55 \mathrm{~m}$ & $2,40 \mathrm{~m}$ & $2,70 \mathrm{~m}^{2}$ \\
\hline 3 & Cozinha/Serviço & $3,90 \mathrm{~m} \times 1,70 \mathrm{~m}$ & $2,40 \mathrm{~m}$ & $6,63 \mathrm{~m}^{2}$ \\
\hline 4 & Sala & $4,14 \mathrm{~m} \times 3,05 \mathrm{~m}$ & $2,40 \mathrm{~m}$ & $14,64 \mathrm{~m}^{2}$ \\
\hline 5 & Quarto 2 & $3,10 \mathrm{~m} \times 2,40 \mathrm{~m}$ & $2,40 \mathrm{~m}$ & $7,44 \mathrm{~m}^{2}$ \\
\hline
\end{tabular}

Fonte: os autores.

Considerando cada ambiente como uma zona térmica a ser simulada, cada apartamento é dividido em cinco zonas térmicas, conforme apresentado na Figura 4.

Para a realização das simulações computacionais, a edificação foi considerada sem entorno construído, simulando-se apenas uma unidade habitacional representativa com cobertura exposta e quartos orientados para oeste. Nas paredes externas aos quartos é inserida uma camada de vegetação (Figura 4). 


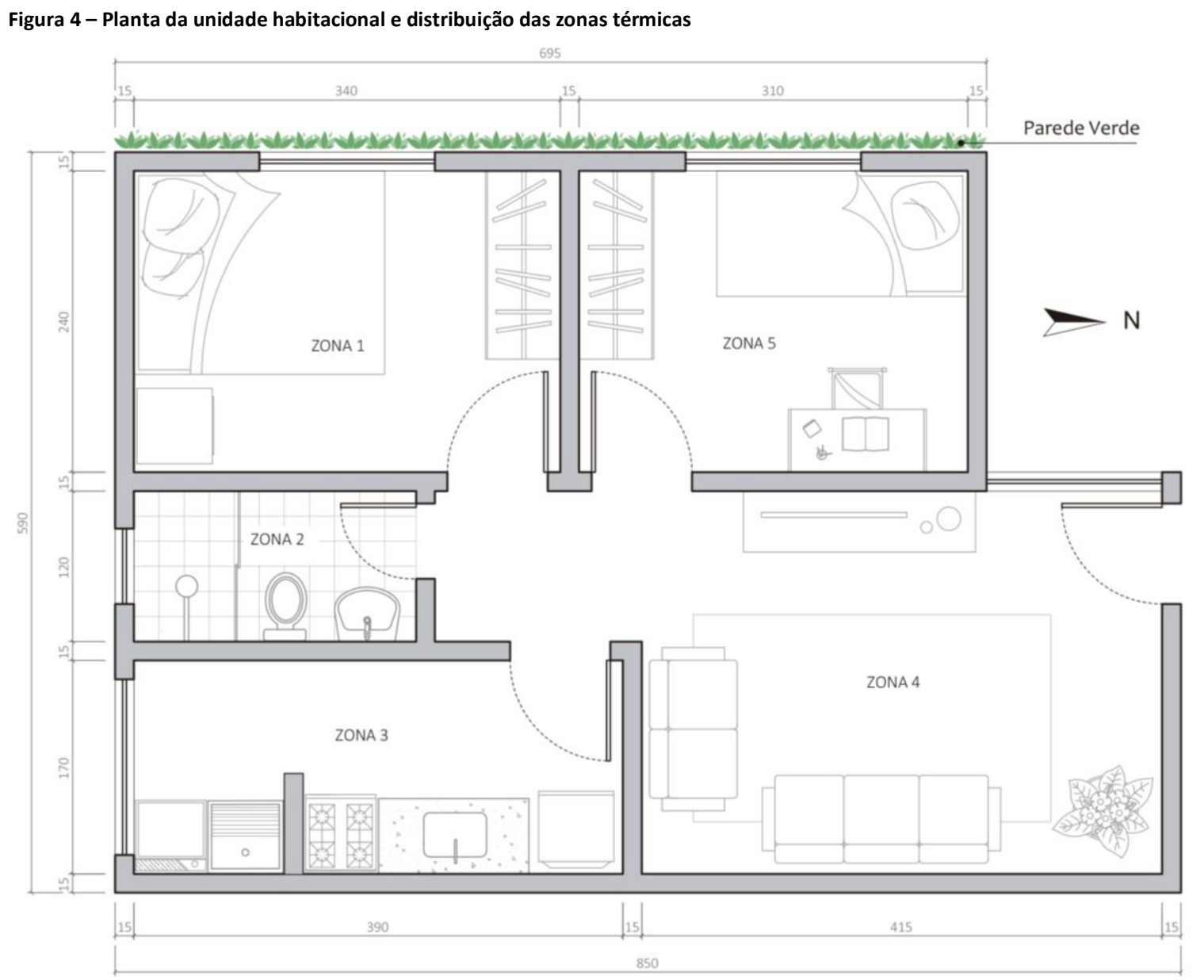

Parâmetros adotados na análise

A avaliação do desempenho térmico do modelo considera as condições climáticas de três zonas bioclimáticas brasileiras: 1, 3 e 8, representadas pelas cidades de Curitiba-PR, São Paulo-SP e Manaus-AM, respectivamente, previstas na norma de desempenho NBR 15.220-3 (ABNT, 2005). Estas zonas são escolhidas em função de suas características, sendo representativas de três climas: Zona Bioclimática 1 (ZB1) - clima extremo de inverno, Zona Bioclimática 8 (ZB8) - clima extremo de verão e Zona Bioclimática 3 (ZB3) - clima intermediário. Na Tabela 2 apresentam-se os dados geográficos das cidades simuladas.

\begin{tabular}{|c|c|c|c|c|}
\hline Zona Bioclimática & Localização estimada & Latitude & Longitude & Altitude \\
\hline 1 & Curitiba (PR) & $\mathrm{S} 25^{\circ} 42^{\prime}$ & $W 49^{\circ} 27^{\prime}$ & $924 \mathrm{~m}$ \\
\hline 3 & São Paulo (SP) & $\mathrm{S} 23^{\circ} 50^{\prime}$ & $W 46^{\circ} 62^{\prime}$ & $792 \mathrm{~m}$ \\
\hline 8 & Manaus (AM) & $\mathrm{S} 3^{\circ} 13^{\prime}$ & W $60^{\circ} 02^{\prime}$ & $72 \mathrm{~m}$ \\
\hline
\end{tabular}

Fonte: Adaptado da NBR 15.575 (ABNT, 2013).

O estudo é realizado levando-se em consideração os critérios da norma de desempenho de edificações habitacionais NBR 15.575 (ABNT, 2013), a qual estabelece que se deve desconsiderar a presença de fontes internas de calor na análise de desempenho térmico, uma vez que está sendo considerado apenas a resposta térmica da envoltória. Sendo assim, neste estudo são desconsiderados os ganhos internos de calor liberados pelos perfis de ocupação, equipamentos e iluminação. 
O estudo é feito para os dias típicos de verão e inverno das zonas bioclimáticas analisadas, conforme estabelecido pela norma NBR 15.575 (ABNT, 2013). Na Tabela 3 apresentam-se os dados dos dias típicos de verão e inverno para as cidades consideradas no estudo.

Tabela 3 - Dias típicos de verão e inverno

\begin{tabular}{|c|c|c|c|c|c|c|c|}
\hline & Zona bioclim & & $\begin{array}{c}\text { Te diária } \\
\operatorname{máx} / \min \left({ }^{\circ} \mathrm{C}\right) \\
\end{array}$ & $\begin{array}{c}\text { Amplitude diária de } \\
\text { temperatura }\left({ }^{\circ} \mathrm{C}\right)\end{array}$ & $\begin{array}{c}\text { Te bulbo } \\
\text { úmido }\left({ }^{\circ} \mathrm{C}\right)\end{array}$ & $\begin{array}{c}\text { Radiação Solar } \\
\left(\mathrm{Wh} / \mathrm{m}^{2}\right)\end{array}$ & $\begin{array}{c}\text { Nebulosidade } \\
\text { (décimos) }\end{array}$ \\
\hline \multirow{2}{*}{1} & \multirow{2}{*}{ Curitiba (PR) } & Verão & 31,4 & 10,2 & 21,3 & 4.988 & 0,8 \\
\hline & & Inverno & 0,7 & 11,6 & 11 & 3.211 & 0,6 \\
\hline \multirow{2}{*}{3} & \multirow{2}{*}{ São Paulo (SP) } & Verão & 31,9 & 9,2 & 21,3 & 5.180 & 0,6 \\
\hline & & Inverno & 6,2 & 10 & 13,4 & 4.418 & 0,6 \\
\hline \multirow{2}{*}{8} & \multirow{2}{*}{ Manaus (AM) } & Verão & 34,9 & 9,1 & 26,4 & 5.177 & 0,7 \\
\hline & & Inverno & 21,4 & 7,9 & 25 & 4.523 & 0,7 \\
\hline
\end{tabular}

Legenda: Te - Temperatura externa. Fonte: Adaptado da NBR 15.575 (ABNT, 2013).

\section{Estratégias de projeto adotadas na análise}

Para a análise da influência da parede verde no desempenho térmico da edificação, é simulado inicialmente um modelo base, sem a camada de vegetação. Posteriormente, buscando analisar e comparar o funcionamento das duas tipologias de parede verde, direta e indireta, o modelo é simulado adicionando-se uma camada de vegetação às paredes externas aos quartos (Figura 4). A vegetação é inserida diretamente às envoltórias, no caso da parede verde direta, e para a parede verde indireta adota-se um afastamento de $20 \mathrm{~cm}$ entre a camada de vegetação e a parede. Neste caso, é utilizado o componente "Surface Property: Exterior Natural Vented Cavity" em conjunto com "Surface Property: Other Side Conditions Model", no programa EnergyPlus que, juntos, permitem calcular as trocas de calor que ocorrem no espaço entre a vegetação e a parede.

Sabendo que a vegetação favorece o aumento da umidade e que esta tem grande influência nas condições térmicas de um edifício, é realizada uma nova simulação. Neste caso, simula-se a edificação com parede verde, utilizando o modelo HAMT do EnergyPlus, que considera o transporte de umidade através da envoltória simultaneamente de/para o meio externo e interno. Para a simulação com o modelo HAMT, as propriedades higrotérmicas dos materiais de construção utilizados, assim como da vegetação, necessárias para a entrada de dados, são retiradas do programa de simulações higrotérmicas WUFI (WUFI, 2019).

Para o fechamento da edificação adota-se a alvenaria convencional em tijolos cerâmicos, por constituir um método de construção amplamente utilizado no Brasil. Os demais materiais de fechamento seguem as especificações do MCMV, que prevê a utilização do piso cerâmico, laje de concreto, janelas de ferro ou alumínio e portas de madeira. No fechamento da cobertura da edificação, é considerada uma camada de impermeabilização por meio de uma membrana betuminosa. Assim, a cobertura é composta das seguintes camadas: reboco, laje de concreto, reboco de regularização, impermeabilização (membrana) e reboco. Os materiais utilizados neste estudo e suas propriedades termofísicas são apresentadas na Tabela 4.

As propriedades termofísicas dos materiais de construção utilizados neste estudo foram retiradas da norma NBR 15.220 (ABNT,2005), enquanto as propriedades termofísicas referentes à vegetação foram retiradas do trabalho de Yoshimi e Altan (2011), que formularam um modelo térmico da trepadeira Hedera Helix usando o software de simulação ambiental ECOTECT. 
SOUSA, Luana Resende de; SOUZA, Henor Artur de; GOMES, Adriano Pinto

Influência de paredes verdes no desempenho térmico de habitações sociais

\begin{tabular}{cccccc} 
Tabela 4- Propriedades dos materiais utilizados & \\
\hline Material & Espessura $(\mathrm{m})$ & $\begin{array}{c}\text { Condutividade } \\
\text { Térmica }(\mathrm{W} / \mathrm{m} . \mathrm{K})\end{array}$ & $\begin{array}{c}\text { Densidade } \\
\left(\mathrm{kg} / \mathrm{m}^{3}\right)\end{array}$ & $\begin{array}{c}\text { Calor específico } \\
(\mathrm{J} / \mathrm{kg} \cdot \mathrm{K})\end{array}$ & $\begin{array}{c}\text { Absortância } \\
\text { Térmica }\end{array}$ \\
\hline Reboco & 0,02 & 1,15 & 1800 & 1000 & 0,3 \\
\hline Bloco Cerâmico & 0,09 & 0,7 & 1000 & 920 & 0,3 \\
\hline Piso Cerâmico & 0,0127 & 0,9 & 1600 & 920 & 0,3 \\
\hline Compensado & 0,035 & 0,15 & 530 & 2300 & 0,9 \\
\hline Concreto & 0,1 & 1,75 & 2200 & 1000 & 0,6 \\
\hline Membrana Betuminosa & 0,004 & 0,23 & 1000 & 1460 & 0,7 \\
\hline Reboco de regularização & 0,01 & 1,15 & 1800 & 1000 & 0,3 \\
\hline Camada de vegetação & 0,001 & 0,002 & 0,4 & 2800 & 0,2 \\
\hline
\end{tabular}

Fonte: Adaptada da NBR 15.220 (ABNT, 2005); YOSHIMI; ALTAN (2011).

A absortância solar da camada externa da envoltória foi definida como $a=0,3$. Na tabela 5 são apresentados os valores de transmitância e capacidade térmica resultantes para os componentes de construção da edificação.

Tabela 5 - Propriedades resultantes por componente de construção

\begin{tabular}{|c|c|c|}
\hline Componentes de Construção: & $\begin{array}{c}\text { Transmitância Térmica } \\
\left(\mathrm{W} / \mathrm{m}^{2} \cdot \mathrm{k}\right)\end{array}$ & Capacidade Térmica $\left(\mathrm{kJ} / \mathrm{m}^{2} . \mathrm{k}\right)$ \\
\hline Cobertura & 8,747 & 315,8 \\
\hline Parede (sem vegetação) & 6,122 & 154,8 \\
\hline Parede Verde Direta & 1,507 & 154,8 \\
\hline Parede Verde Indireta & 1,214 & 154,8 \\
\hline
\end{tabular}

Fonte: Adaptada de DOE, 2019.

\section{Parâmetros de simulação}

Todos os recintos da unidade habitacional são simulados, considerando as trocas térmicas e de massa entre os ambientes e, observando-se as indicações da norma NBR 15.575 (ABNT, 2013) em relação a uma taxa de ventilação constante, atribui-se a taxa de renovação de ar de $1 \mathrm{ren} / \mathrm{h}$. Os resultados encontrados, no entanto, são mostrados apenas para a Zona 1 - quarto 1 (Figura 3 e Figura 4), por se tratar de um ambiente de permanência prolongada, para as três zonas bioclimáticas no verão. No inverno, os resultados são apresentados somente para as zonas bioclimáticas 1 e 3 pois, como indicado pela norma NBR 15.220 (ABNT, 2005), a avaliação do desempenho térmico para a Zona Bioclimática 8 no inverno não é necessária, já que esta zona não apresenta temperaturas baixas nesse período, mas uma média diária de $25^{\circ} \mathrm{C}$.

Os resultados obtidos para a temperatura interna são comparados entre si e, posteriormente, comparados aos critérios mínimos estabelecidos pela norma NBR 15.575 (ABNT, 2013). Além da temperatura do ar interno, analisa-se também a temperatura superficial interna da parede onde é inserida a camada de vegetação, comparando-se os valores encontrados com aqueles referentes à mesma parede sem vegetação.

\section{Resultados}

A partir dos resultados obtidos, pode-se analisar a influência da parede verde na temperatura interna da edificação. Os resultados apresentados (Figura 5 a Figura 12) são comparações entre as temperaturas internas e superficiais internas para o modelo no caso base (sem presença de vegetação na envoltória) e do modelo com parede verde (vegetação na envoltória), para as três zonas bioclimáticas analisadas (ZB1, ZB3 e ZB8). 


\section{Parede Verde Direta}

A presença da parede verde direta propicia comportamentos parecidos no perfil de temperatura nas três zonas bioclimáticas consideradas. Na figura 5 mostra-se a variação da temperatura interna dos modelos analisados no dia típico de verão para as zonas bioclimáticas ZB1, ZB3 e ZB8, respectivamente. Pode-se observar que, no horário da temperatura interna mais alta, em torno das 18 horas, o uso da camada de vegetação na envoltória manteve as temperaturas internas mais baixas se comparadas ao caso base, obtendo-se uma diminuição de temperatura de até $0,7{ }^{\circ} \mathrm{C}$. Estes resultados já demonstram o potencial da parede verde como minimizador do ganho de calor da edificação, apenas como um mecanismo de sombreamento, barreira ao vento e isolamento térmico. No entanto, ao se considerar na simulação o efeito da transferência de umidade através da envoltória, utilizando-se o modelo HAMT, percebe-se a grande influência do mecanismo de evapotranspiração das plantas na diminuição da temperatura interna da edificação, de modo que a diferença de temperatura pode chegar a $2,0^{\circ} \mathrm{C}$ para a zona bioclimática ZB1, $1,7{ }^{\circ} \mathrm{C}$ para a zona bioclimática ZB3 e a $2,4^{\circ} \mathrm{C}$ para a zona bioclimática ZB8.

No período noturno, por volta das 5 horas, a edificação com parede verde direta apresentou temperaturas internas mais amenas, até $0,6^{\circ} \mathrm{C}$ maior que o caso base. No entanto, utilizando o modelo HAMT obteve-se uma pequena diminuição das temperaturas internas, de até $0,3^{\circ} \mathrm{C}$ em comparação ao caso base.

Figura 5 - Evolução temporal da temperatura interna do modelo com parede verde direta para verão: (a) ZB 1, (b) ZB 3 e (c) ZB 8

(a)

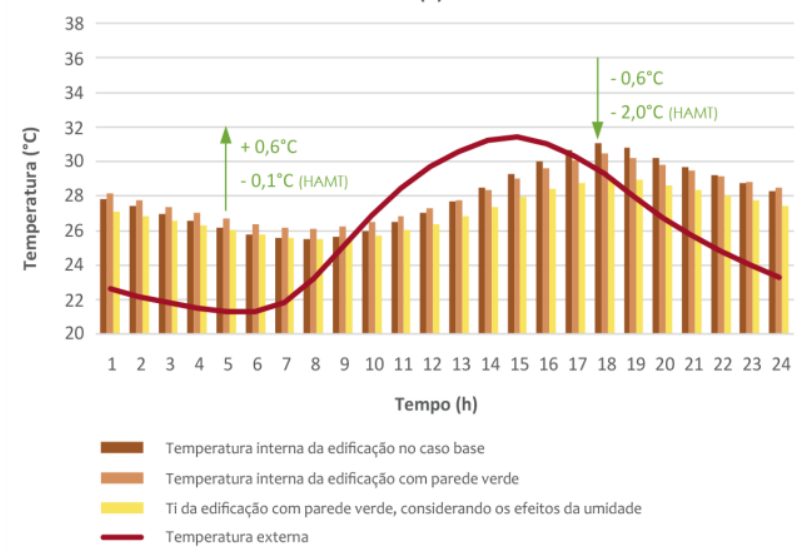

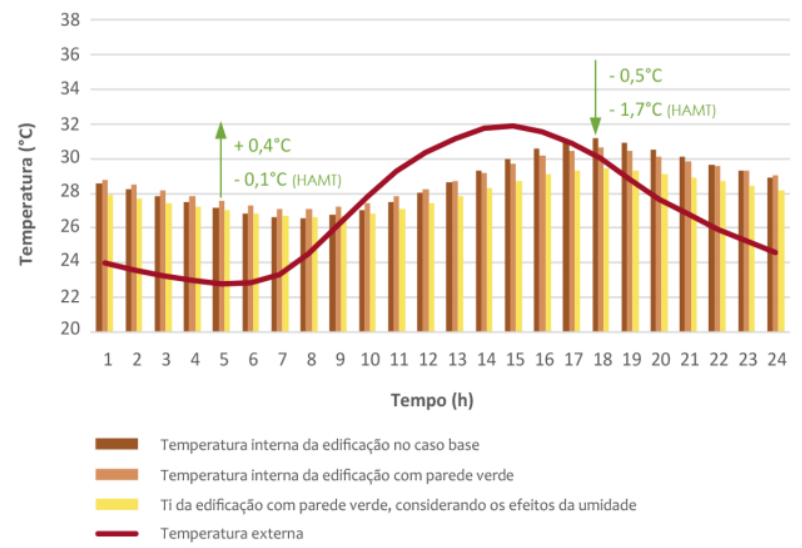

(c)

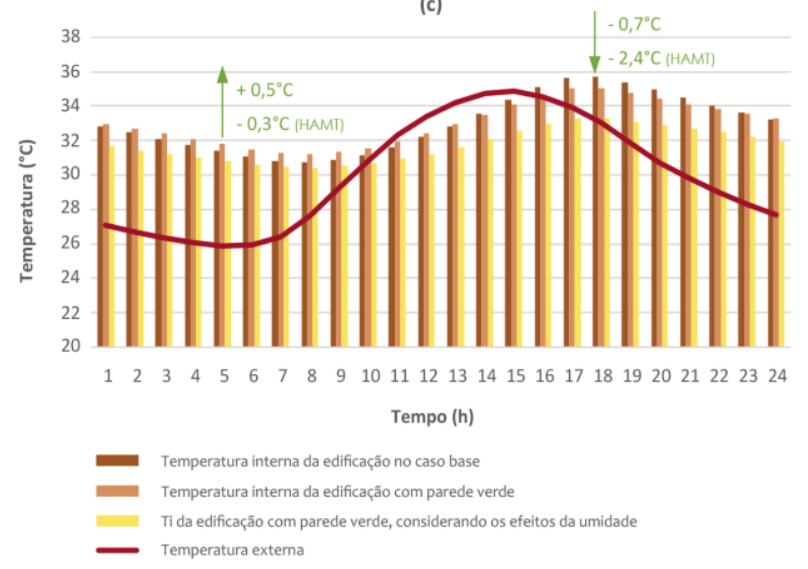

Fonte: os autores. 
No dia típico de inverno (Figura 6), observa-se que os valores de temperatura interna do modelo com parede verde direta seguiram a mesma tendência, apresentando temperaturas internas mais amenas no período noturno (aumento de até $0,5^{\circ} \mathrm{C}$ ), e temperaturas internas mais baixas no período mais quente do dia (diminuição de até o,6 ${ }^{\circ} \mathrm{C}$ ), quando comparados aos valores encontrados no caso base. Utilizando o modelo HAMT, pode-se notar uma diminuição de até $1,4^{\circ} \mathrm{C}$ no período mais quente do dia e um aumento de até $0,5^{\circ} \mathrm{C}$ no período noturno, em relação ao caso base.

Figura 6 - Evolução temporal da temperatura interna do modelo com parede verde direta para inverno: (a) ZB1 e (b) ZB

(a)

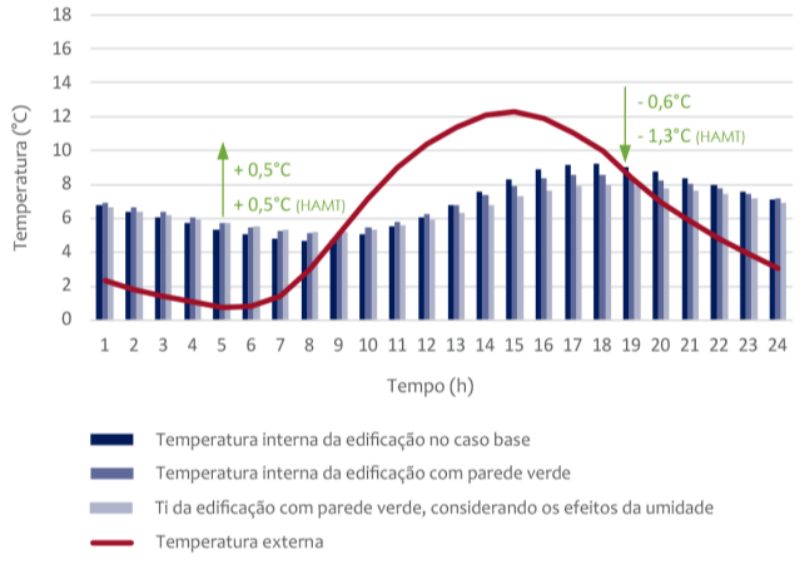

(b)

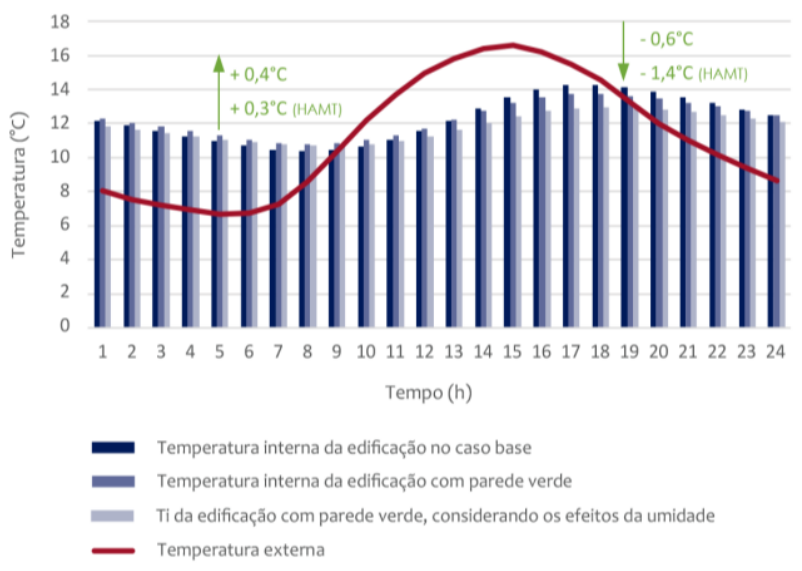

Fonte: os autores.

Para as temperaturas superficiais internas no dia típico de verão (Figura 7), observa-se que durante o período com as temperaturas superficiais mais altas, entre 15 e 19 horas, a superfície da parede sem vegetação apresentou uma temperatura mais alta que a superfície com parede verde, ou seja, o fluxo de calor transmitido pelas paredes foi reduzido pela camada de vegetação. Obteve-se reduções de até $3,0^{\circ} \mathrm{C}$ para a edificação com parede verde e de até $3,7^{\circ} \mathrm{C}$ ao se considerar o efeito da umidade. Durante a noite, as temperaturas superficiais do modelo com parede verde direta mantiveram-se mais altas que o caso base, atingindo um aumento de até $2,8^{\circ} \mathrm{C}$ para o modelo com parede verde. Ao se utilizar o modelo HAMT, o aumento apresentado foi de até $1,1^{\circ} \mathrm{C}$ em comparação ao caso base.

Na Figura 8 apresentam-se os valores de temperatura superficial interna para o modelo, no dia típico de inverno. Os valores para os dois casos (ZB1 e ZB3) apresentaram reduções de até $2,9^{\circ} \mathrm{C} \mathrm{e} 2,5^{\circ} \mathrm{C}$ na temperatura superficial interna durante o período mais quente do dia, para a edificação com parede verde e considerando-se o efeito da umidade, respectivamente. No período noturno, especificamente entre meia-noite e 9 horas, as temperaturas encontradas para os dois modelos com parede verde foram maiores que as temperaturas no caso base, o que demonstra a capacidade da camada de vegetação de reduzir a perda de calor da edificação. Observa-se que a edificação com parede verde apresentou um aumento da temperatura superficial de até $2,5{ }^{\circ} \mathrm{C}$. Considerando o efeito da umidade o aumento encontrado foi de até $1,3{ }^{\circ} \mathrm{C}$. 
Figura 7 - Evolução temporal da temperatura superficial interna do modelo com parede verde direta para verão: (a) ZB1, (b) ZB3 e (c) ZB8

(a)

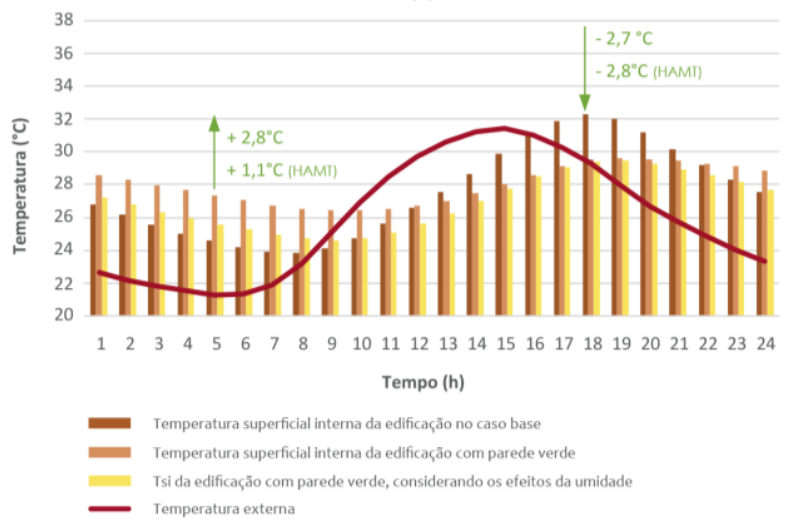

(b)

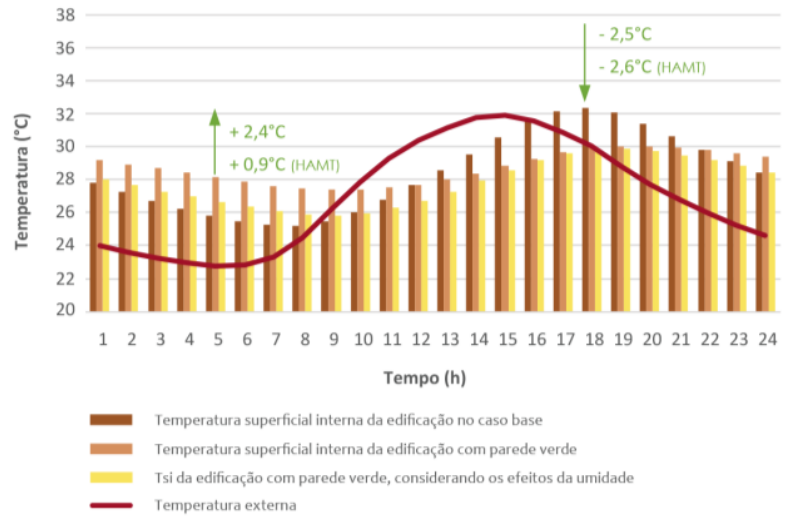

(c)

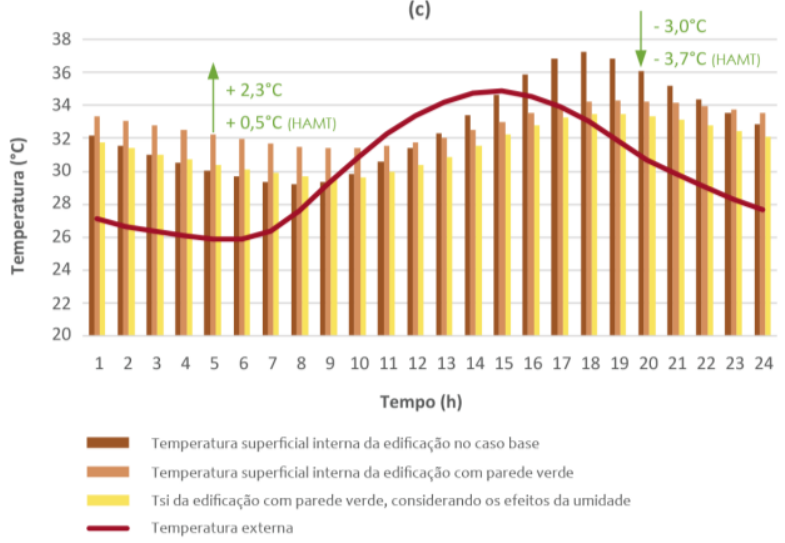

Fonte: os autores.

Figura 8 - Evolução temporal da temperatura superficial interna do modelo com parede verde direta para inverno: (a) ZB 1 e (b) ZB 3

(a)

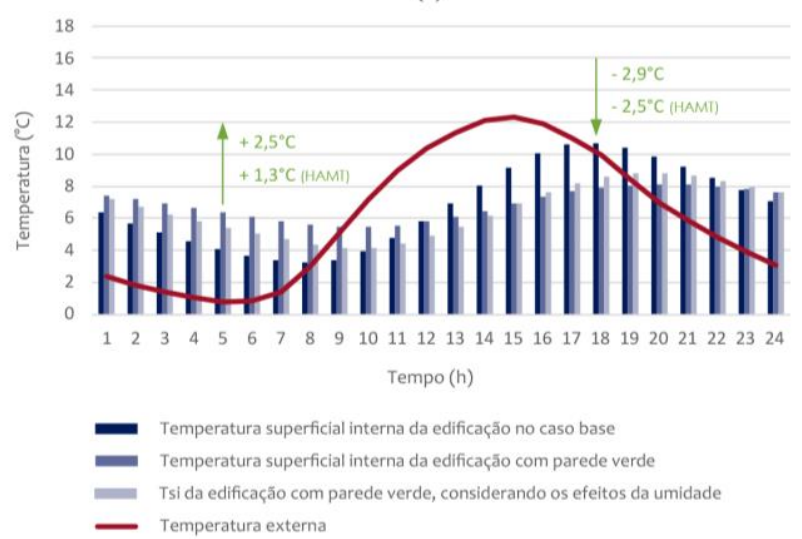

(b)

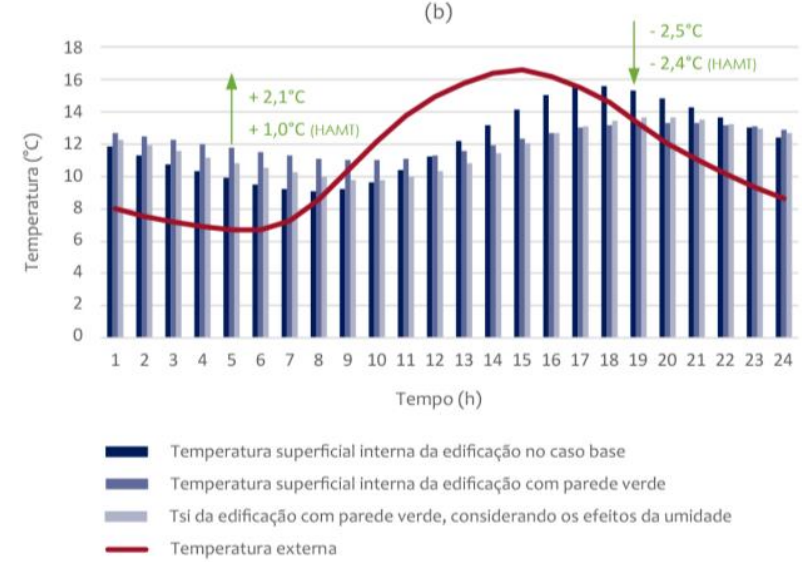

Fonte: os autores.

\section{Parede Verde Indireta}

No caso da parede verde indireta, os resultados obtidos apresentaram comportamentos semelhantes àqueles obtidos para o modelo com parede verde direta. Pode-se notar que, para o dia típico de verão (Figura 9), por volta do horário de temperatura interna mais alta, em torno das 18 horas, a camada de vegetação manteve as temperaturas internas mais baixas, proporcionando uma redução de até $0,8^{\circ} \mathrm{C}$. Ao se considerar o efeito da umidade, essa diferença de temperatura chegou a $2,9^{\circ} \mathrm{C}$. 
Durante a noite, a edificação com parede verde indireta apresentou temperaturas internas mais amenas, até $0,4{ }^{\circ} \mathrm{C}$ maior que no modelo sem vegetação. Para a simulação utilizando o modelo HAMT, obteve-se um pequeno aumento de $0,2{ }^{\circ} \mathrm{C}$ para a zona bioclimática ZB1, enquanto nas zonas bioclimáticas ZB3 e ZB8, obteve-se temperaturas mais baixas àquelas encontradas no caso base, apresentando reduções de até $0,8^{\circ} \mathrm{C}$.

Figura 9 - Evolução temporal da temperatura interna do modelo com parede verde indireta para verão: (a) ZB 1, (b) ZB 3 e (c) ZB 8

(a)

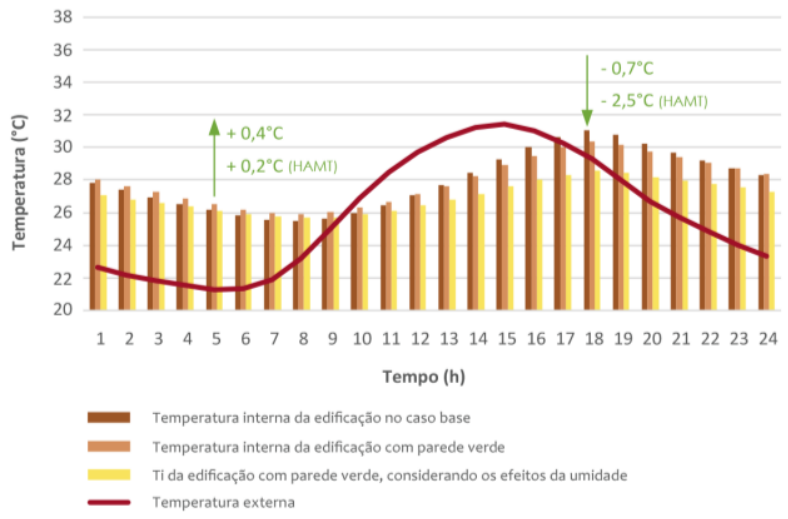

(b)

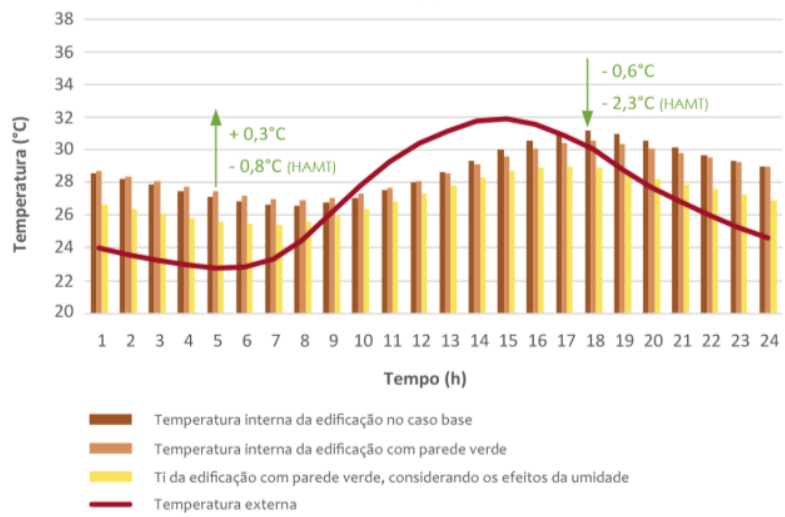

(c)

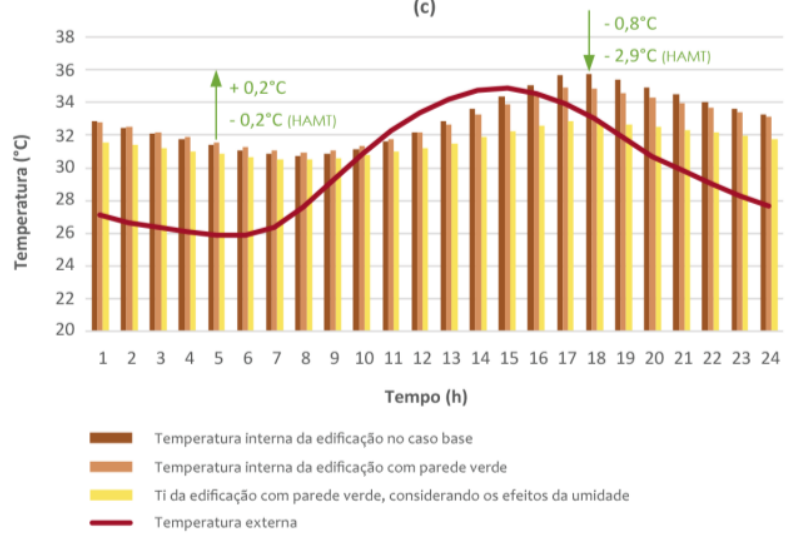

Fonte: os autores.

Observando os resultados apresentados na Figura 10, nota-se que, para o dia típico de inverno, os valores de temperatura interna do modelo com parede verde indireta seguiram a mesma tendência, apresentando redução da temperatura interna nas horas mais quentes do dia (diminuição de até $0,6{ }^{\circ} \mathrm{C}$ ) e elevação da temperatura interna durante o período noturno (aumento de até $0,3{ }^{\circ} \mathrm{C}$ ). Para a simulação utilizando o modelo HAMT, nota-se uma diminuição de até $1,6^{\circ} \mathrm{C}$ na temperatura interna, durante 0 período mais quente do dia. No período noturno, nota-se um aumento de até $0,8^{\circ} \mathrm{C}$ para a zona bioclimática ZB1 e uma diminuição de até $1,0^{\circ} \mathrm{C}$ para a zona bioclimática ZB3. 
Figura 10 - Evolução temporal da temperatura interna do modelo com parede verde indireta para inverno: (a) ZB 1 e (b) ZB 3

(a)

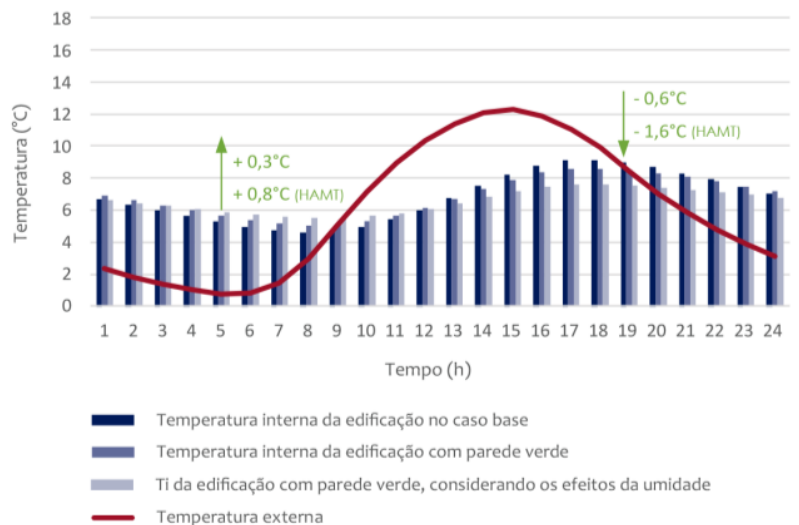

(b)

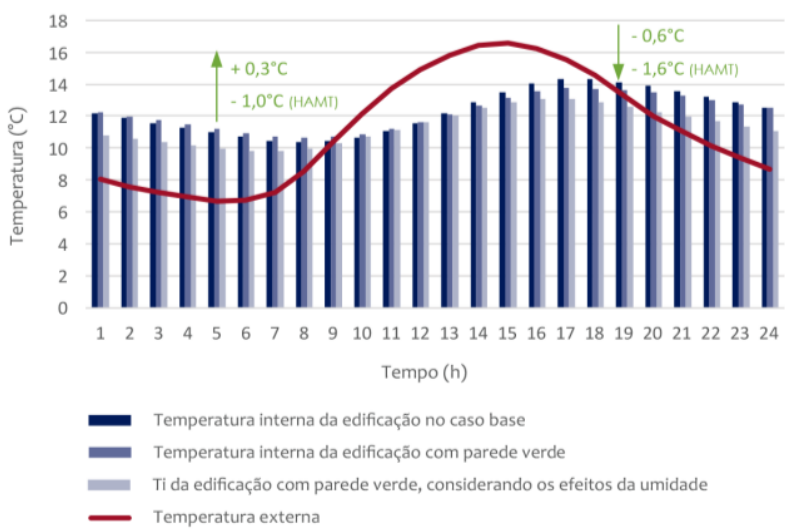

Fonte: os autores.

Para as paredes verdes indiretas, as temperaturas superficiais internas encontradas para o dia típico de verão (Figura 11) também demonstraram que a adoção da parede verde reduz o fluxo de calor transmitido para o interior da edificação. Durante as horas mais quentes do dia, observaram-se reduções de até $3,3^{\circ} \mathrm{C}$ para a edificação com parede verde indireta e de até $5,5^{\circ} \mathrm{C}$ ao se considerar o efeito da umidade.

No período noturno, as temperaturas superficiais para o modelo com parede verde indireta mantiveram-se mais elevadas do que no caso base, atingindo um aumento de até $2,1^{\circ} \mathrm{C} \mathrm{e} 1,9^{\circ} \mathrm{C}$ para o modelo com parede verde e ao considerar o efeito da umidade, respectivamente.

Figura 11 - Evolução temporal da temperatura superficial interna do modelo com parede verde indireta para verão: (a) ZB1, (b) ZB3 e (c) ZB8

(a)

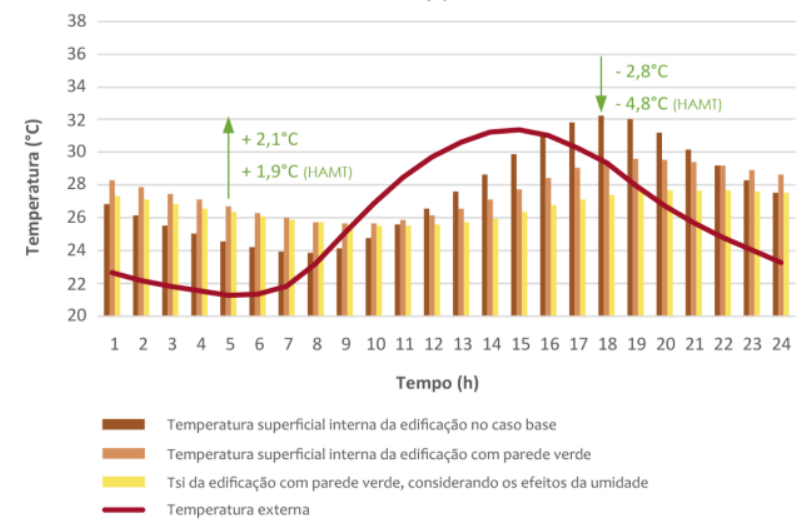

(b)

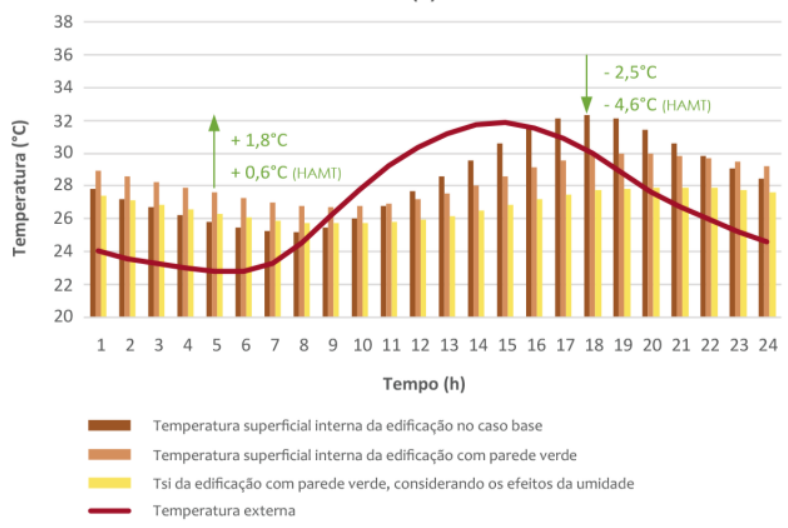

(c)

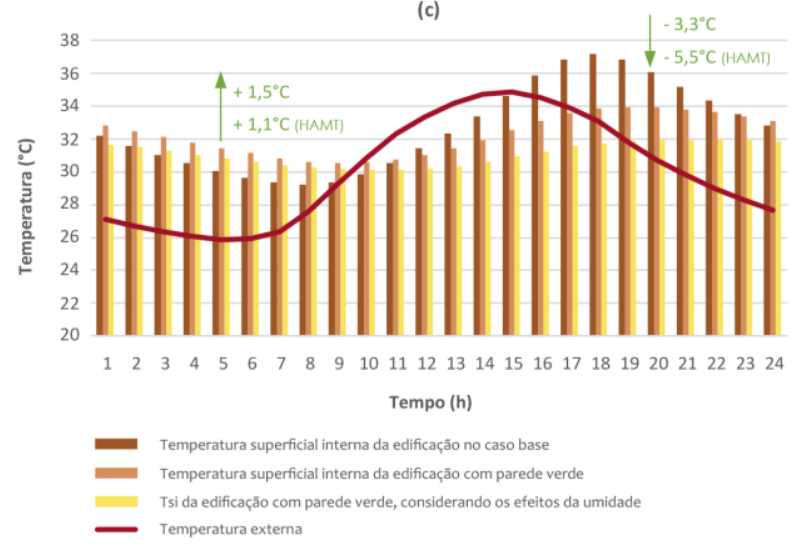

Fonte: os autores. 
Os resultados obtidos para as temperaturas superficiais internas no dia típico de inverno durante as horas mais quentes do dia, mostrados na Figura 12, apresentaram reduções de até $2,6{ }^{\circ} \mathrm{C}$ e $4,0^{\circ} \mathrm{C}$ para o modelo com parede verde e ao se considerar o efeito a umidade, respectivamente. No período noturno, as temperaturas superficiais mantiveram-se mais altas para os dois modelos com parede verde indireta, em comparação ao caso base. Houve um aumento da temperatura superficial interna de até $1,9^{\circ} \mathrm{C}$ para a edificação com parede verde indireta e de até $2,4{ }^{\circ} \mathrm{C}$ na simulação com o modelo HAMT.

Figura 12 - Evolução temporal da temperatura superficial do modelo com parede verde indireta para inverno: (a) ZB1 e (b) ZB3

(a)

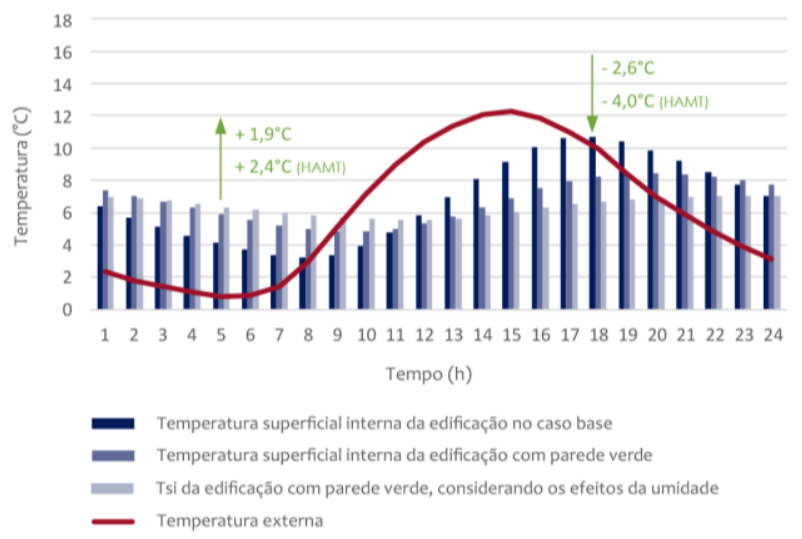

Fonte: os autores.

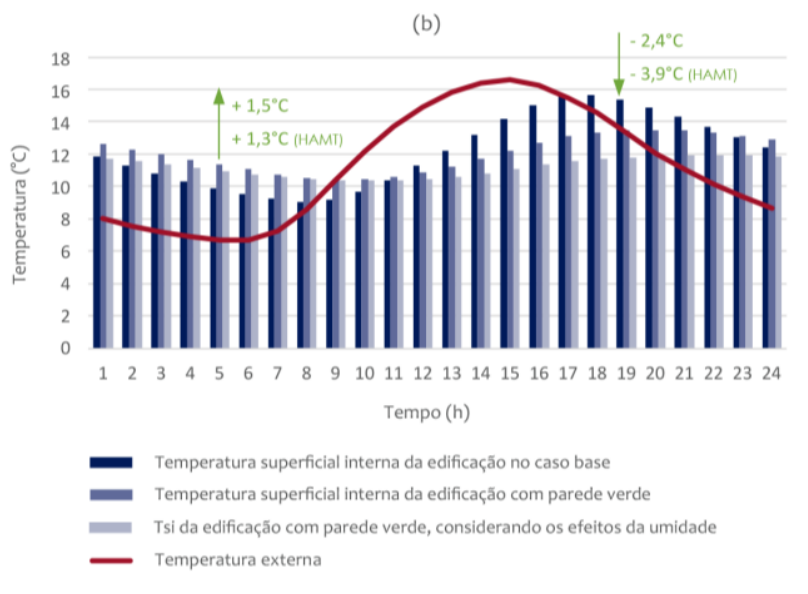

\section{Discussão}

Nota-se que, para as três zonas bioclimáticas analisadas, obteve-se desempenhos térmicos semelhantes nos dias típicos de verão e inverno, com diminuição da temperatura interna durante o dia e amenização da temperatura interna durante a noite, para as duas tipologias de paredes verdes. Embora algumas simulações com o modelo HAMT tenham apresentado uma diminuição da temperatura interna no período noturno se comparada às temperaturas no caso base, de modo geral, estas foram muito semelhantes e, ainda assim, superiores à temperatura exterior.

Com os valores de temperatura encontrados, percebe-se que os dois modelos de parede verde proporcionaram temperaturas internas mais amenas do que àquelas proporcionadas pelo caso base, ou seja, sem parede verde. Na Tabela 6 são apresentadas as temperaturas internas, máximas no verão e mínimas no inverno, em função das duas tipologias de parede verde analisadas. Quando não se considera os efeitos da umidade através da envoltória, os resultados encontrados para as duas tipologias de parede verde foram muito semelhantes, apresentando uma diferença desprezível. No entanto, para a simulação utilizando-se o modelo HAMT, pode-se perceber um melhor desempenho térmico da parede verde indireta, obtendo-se valores máximos de temperatura interna até $0,5^{\circ} \mathrm{C}$ mais baixos do que aqueles proporcionados pela parede verde direta. 


\begin{tabular}{|c|c|c|c|c|c|c|c|}
\hline \multirow{2}{*}{\multicolumn{2}{|c|}{ Zona }} & \multirow{2}{*}{$\begin{array}{c}\text { Temperatura } \\
\text { externa }\left({ }^{\circ} \mathrm{C}\right)\end{array}$} & \multirow{2}{*}{$\begin{array}{c}\text { Caso base } \\
\left({ }^{\circ} \mathrm{C}\right)\end{array}$} & \multicolumn{2}{|c|}{ Edificação com parede verde } & \multicolumn{2}{|c|}{ Considerando a umidade } \\
\hline & & & & DIRETA $\left({ }^{\circ} \mathrm{C}\right)$ & INDIRETA $\left({ }^{\circ} \mathrm{C}\right)$ & DIRETA $\left({ }^{\circ} \mathrm{C}\right)$ & INDIRETA $\left({ }^{\circ} \mathrm{C}\right)$ \\
\hline \multirow[t]{2}{*}{ ZB 1} & Verão & 31,4 & 31,0 & 30,4 & 30,4 & 29,1 & 28,6 \\
\hline & Inverno & 0,8 & 4,7 & 5,2 & 5,0 & 5,2 & 5,5 \\
\hline \multirow[t]{2}{*}{ ZB 3} & Verão & 31,9 & 31,2 & 30,6 & 30,6 & 29,4 & 29,0 \\
\hline & Inverno & 6,7 & 10,4 & 10,8 & 10,6 & 10,7 & 9,8 \\
\hline ZB 8 & Verão & 34,9 & 35,7 & 35,1 & 34,9 & 33,3 & 32,9 \\
\hline
\end{tabular}

Para a zona bioclimática 3 (ZB3), por exemplo, representativa de um clima intermediário, o modelo com parede verde indireta manteve a temperatura interna no valor máximo de $30,6{ }^{\circ} \mathrm{C}$, mesmo valor encontrado para o modelo com parede verde direta, enquanto no caso base chegou-se ao valor de $31,2^{\circ} \mathrm{C}$. Considerando o efeito da transferência de umidade na envoltória, esse valor da temperatura interna diminuiu para $29,4{ }^{\circ} \mathrm{C}$ e $29,0{ }^{\circ} \mathrm{C}$ para a parede verde direta e indireta, respectivamente. Pode-se atribuir este melhor desempenho térmico da parede indireta, utilizando-se o modelo HAMT, à ação conjunta do efeito da umidade e da camada de ar existente entre a folhagem e a parede, a qual passa a funcionar como uma fachada ventilada e interfere na transferência de calor através da parede.

É possível perceber que o uso das paredes verdes proporciona melhores resultados para as localidades de climas quentes, visto que no período de inverno a vegetação é responsável por diminuir a temperatura interna diurna, enquanto o interessante seria captar e manter o calor no interior do edifício. No entanto, embora apresente resultados menos expressivos no inverno, as paredes verdes auxiliaram na redução da perda de calor da edificação, ajudando a manter o calor em seu interior por mais tempo durante a noite. Estudos como o de Otellé e Perini (2017) também comprovam este mecanismo de regulação térmica: por meio de uma pesquisa experimental que avalia o comportamento de diferentes tipologias de jardim vertical, obteve-se um aumento de $1,7{ }^{\circ} \mathrm{C}$ na temperatura superficial interna para o modelo com parede verde direta, sob condições de inverno.

O uso das paredes verdes também proporcionou um atraso térmico médio de 2 horas, em relação às temperaturas superficiais do modelo sem parede verde, contribuindo para um melhor desempenho térmico da edificação. Trabalhos experimentais como os de Morelli (2016) e Matheus et al. (2016), também indicam que as paredes verdes proporcionam atraso térmico nas temperaturas superficiais da parede com vegetação.

Outros estudos comprovam a capacidade de redução da temperatura interna da edificação, por meio da utilização de paredes verdes: Matheus et al. (2016), por meio de pesquisa experimental realizada na cidade de Campinas, SP, encontraram uma redução de cerca de $1,3{ }^{\circ} \mathrm{C}$ na temperatura interna média de uma edificação com a presença de parede verde direta, quando comparada a uma edificação semelhante sem vegetação na fachada. Os resultados de Pérez et al. (2017) para a temperatura interna de protótipos com a presença de parede verde indireta em condições de verão apresentaram reduções máximas de $2,5^{\circ} \mathrm{C}$ na temperatura interna do modelo.

Para as temperaturas superficiais internas, os resultados obtidos também seguem a tendência de resultados obtidos em outros trabalhos: Eumorfopolou e Kontoleon (2009), por exemplo, em uma pesquisa realizada na Grécia durante o período de verão acerca do desempenho de paredes verdes diretas, encontraram uma redução média da temperatura superficial de $0,9^{\circ} \mathrm{C}$, ou seja, cerca $3,5 \%$ de redução, enquanto as reduções médias da temperatura superficial encontradas neste trabalho, encontram-se em torno de 4,3\% e 5,2\%. Outro exemplo, é o trabalho de Yang et al. (2008), realizado na China, 
também durante o período de verão, com paredes verdes indiretas, onde encontraramse reduções de até $2{ }^{\circ} \mathrm{C}$, ou seja, cerca de $6,6 \%$ de redução, para a temperatura superficial interna.

Na Tabela 7 são comparados os critérios mínimos de avaliação de desempenho térmico da norma NBR 15.575 (ABNT, 2013) em relação às temperaturas internas para os casos simulados, nas três zonas bioclimáticas, para a tipologia de parede verde direta. Como se pode perceber, para a zona bioclimática ZB8, os critérios mínimos recomendados pela norma de desempenho apenas foram atendidos para a edificação com parede verde cuja simulação considera os efeitos da umidade. Nas zonas bioclimáticas ZB1 e ZB3, o caso base já atendeu aos critérios mínimos de desempenho térmico para as condições de verão. No entanto, observa-se que, para a edificação com parede verde considerando-se o efeito da umidade, as condições internas atenderam também ao nível intermediário de desempenho térmico. Para as condições de inverno, as temperaturas mínimas encontradas nas análises da zona bioclimática ZB1 e ZB3 atenderam ao nível mínimo de desempenho, para os três casos simulados.

\begin{tabular}{|c|c|c|c|c|c|c|}
\hline \multicolumn{2}{|c|}{ Zona } & Norma & $\begin{array}{c}\text { Temperatura } \\
\text { Externa }\end{array}$ & Caso base & $\begin{array}{l}\text { Edificação com } \\
\text { Parede Verde }\end{array}$ & $\begin{array}{l}\text { Considerando o efeito } \\
\text { da umidade }\end{array}$ \\
\hline \multirow{2}{*}{ ZB 1} & Verão & $\mathrm{T}_{\mathrm{i}, \text { máx }} \leq \mathrm{T}_{\mathrm{e}, \text { máx }}$ & $31,4^{\circ} \mathrm{C}$ & $30,6^{\circ} \mathrm{C} \leq \mathrm{T}_{\mathrm{e}, \text { máx }}$ & $30,4^{\circ} \mathrm{C} \leq \mathrm{T}_{\mathrm{e}, \text { máx }}$ & $29,1^{\circ} \mathrm{C} \leq \mathrm{T}_{\mathrm{e} \text {,máx }}$ \\
\hline & Inverno & $\mathrm{T}_{\mathrm{i}, \min } \geq\left(\mathrm{Te}_{\mathrm{e} \min }+3^{\circ} \mathrm{C}\right)$ & $0,8^{\circ} \mathrm{C}$ & $4,7^{\circ} \mathrm{C} \geq \mathrm{Te}_{\mathrm{e}, \min }+3^{\circ} \mathrm{C}$ & $5,2^{\circ} \mathrm{C} \geq \mathrm{Te}_{\mathrm{e}, \min }+3^{\circ} \mathrm{C}$ & $5,2^{\circ} \mathrm{C} \geq \mathrm{Te}, \min +3{ }^{\circ} \mathrm{C}$ \\
\hline \multirow{2}{*}{ ZB 3} & Verão & $T_{i, \text { máx }} \leq T_{e, \text { máx }}$ & $31,9^{\circ} \mathrm{C}$ & $31,2^{\circ} \mathrm{C} \leq \mathrm{T}_{\mathrm{e}, \text { máx }}$ & $30,6^{\circ} \mathrm{C} \leq \mathrm{T}_{\mathrm{e}, \text { máx }}$ & $29,4^{\circ} \mathrm{C} \leq \mathrm{T}_{\mathrm{e}, \text { máx }}$ \\
\hline & Inverno & $\mathrm{T}_{\mathrm{i}, \min } \geq\left(\mathrm{Te}_{\mathrm{m} \text { min }}+3^{\circ} \mathrm{C}\right)$ & $6,7^{\circ} \mathrm{C}$ & $10,4^{\circ} \mathrm{C} \geq \mathrm{Te}, \min +3{ }^{\circ} \mathrm{C}$ & $10,8^{\circ} \mathrm{C} \geq \mathrm{Te}_{\min }+3{ }^{\circ} \mathrm{C}$ & $10,7^{\circ} \mathrm{C} \geq \mathrm{Te}_{\min }+3{ }^{\circ} \mathrm{C}$ \\
\hline ZB 8 & Verão & $\mathrm{T}_{\mathrm{i}, \text { máx }} \leq \mathrm{T}_{\mathrm{e} \text {,máx }}$ & $34,9^{\circ} \mathrm{C}$ & $35,7^{\circ} \mathrm{C} \geq \mathrm{T}_{\mathrm{e} \text {,máx }}$ & $35,1^{\circ} \mathrm{C} \geq \mathrm{T}_{\mathrm{e} \text {,máx }}$ & $33,3^{\circ} \mathrm{C} \leq \mathrm{T}_{\mathrm{e}, \text { máx }}$ \\
\hline
\end{tabular}

Da mesma forma, com a utilização da parede verde indireta foi possível atingir os requisitos mínimos de desempenho térmico recomendados pela norma NBR 15.575 (ABNT, 2013) nas três zonas bioclimáticas analisadas (ZB1, ZB3 e ZB8), como indicado na Tabela 8. Neste caso, a edificação com parede verde indireta na ZB8 atendeu não só o nível mínimo de desempenho, como o nível intermediário. Para as condições de verão, considerando o efeito da umidade, a parede verde indireta também conseguiu atender o critério de nível intermediário de desempenho térmico nas zonas bioclimáticas ZB1 e ZB3, e ao nível superior de desempenho na zona ZB8.

\begin{tabular}{|c|c|c|c|c|c|c|}
\hline \multicolumn{2}{|c|}{ Zona } & Norma & $\begin{array}{c}\text { Temperatura } \\
\text { Externa }\end{array}$ & Caso base & $\begin{array}{l}\text { Edificação com } \\
\text { Parede Verde }\end{array}$ & $\begin{array}{c}\text { Considerando o efeito } \\
\text { da umidade }\end{array}$ \\
\hline \multirow{2}{*}{ ZB 1} & Verão & $T_{i, \text { máx }} \leq T_{e, \text { máx }}$ & $31,4^{\circ} \mathrm{C}$ & $30,6^{\circ} \mathrm{C} \leq \mathrm{T}_{\mathrm{e}, \text { máx }}$ & $30,4^{\circ} \mathrm{C} \leq \mathrm{T}_{\mathrm{e}, \text { máx }}$ & $28,6^{\circ} \mathrm{C} \leq \mathrm{T}_{\mathrm{e}, \mathrm{máx}}$ \\
\hline & Inverno & $\mathrm{T}_{\mathrm{i}, \min } \geq\left(\mathrm{Te}_{\mathrm{e}, \min }+3^{\circ} \mathrm{C}\right)$ & $0,8^{\circ} \mathrm{C}$ & $4,7^{\circ} \mathrm{C} \geq \mathrm{Te}_{\mathrm{e}, \min }+3^{\circ} \mathrm{C}$ & $5,0^{\circ} \mathrm{C} \geq \mathrm{Te}_{\mathrm{e}, \min }+3{ }^{\circ} \mathrm{C}$ & $5,5^{\circ} \mathrm{C} \geq \mathrm{Te}, \min +3{ }^{\circ} \mathrm{C}$ \\
\hline \multirow{2}{*}{ ZB 3} & Verão & $T_{i, \text { máx }} \leq T_{e, \text { máx }}$ & $31,9^{\circ} \mathrm{C}$ & $31,2^{\circ} \mathrm{C} \leq \mathrm{T}_{\mathrm{e}, \text { máx }}$ & $30,6^{\circ} \mathrm{C} \leq \mathrm{T}_{\mathrm{e}, \text { máx }}$ & $29,0^{\circ} \mathrm{C} \leq \mathrm{T}_{\mathrm{e}, \text { máx }}$ \\
\hline & Inverno & $\mathrm{T}_{\mathrm{i}, \min } \geq\left(\mathrm{Te}_{\mathrm{e}, \min }+3^{\circ} \mathrm{C}\right)$ & $6,7^{\circ} \mathrm{C}$ & $10,4^{\circ} \mathrm{C} \geq \mathrm{Te}, \min +3{ }^{\circ} \mathrm{C}$ & $10,6^{\circ} \mathrm{C} \geq \mathrm{Te}_{\mathrm{e}, \min }+3^{\circ} \mathrm{C}$ & $9,8^{\circ} \mathrm{C} \geq \mathrm{Te}_{\min }+3{ }^{\circ} \mathrm{C}$ \\
\hline ZB 8 & Verão & $\mathrm{T}_{\mathrm{i}, \text { máx }} \leq \mathrm{T}_{\mathrm{e} \text {,máx }}$ & $34,9^{\circ} \mathrm{C}$ & $35,7^{\circ} \mathrm{C} \geq \mathrm{T}_{e, \text { máx }}$ & $34,9^{\circ} \mathrm{C} \leq \mathrm{T}_{\mathrm{e}, \text { máx }}$ & $32,9^{\circ} \mathrm{C} \leq \mathrm{T}_{e, \text { máx }}$ \\
\hline
\end{tabular}

É importante salientar que o programa EnergyPlus apresenta certas limitações na representação da camada de vegetação, de modo que aspectos importantes como densidade e intensidade da folhagem não são aqui considerados. Além disso, há carência de dados referentes às propriedades termofísicas e higrotérmicas de espécies trepadeiras, principalmente no Brasil, sendo necessário recorrer a dados obtidos em outros países. Vale ressaltar ainda que a avaliação de desempenho térmico de edificações residenciais pelo método de simulação computacional recomendado pela Norma NBR 15.575 (ABNT, 2013), também apresenta limitações, já que o método recomendado não avalia as condições de uso real da edificação, por exemplo, ao 
desconsiderar as cargas internas de ocupação, iluminação e equipamentos e/ou estabelecer uma taxa fixa de renovação do ar.

\section{Conclusão}

A partir dos resultados obtidos nesse presente trabalho demonstra-se que existe uma diferença na temperatura interna dos ambientes decorrente dos dois arranjos na fachada: com e sem vegetação. A parede verde, portanto, apresenta-se como uma camada que diminui as trocas de calor entre os meios interno e externo, ajudando a manter baixa a temperatura interna do ambiente durante o dia e amena durante a noite, resultando em uma menor amplitude térmica diária para os climas aqui analisados.

Com base nos resultados, aqui obtidos sem considerar as cargas internas da edificação, percebe-se também que as paredes verdes apresentam maior eficácia no verão e em regiões mais quentes, visto que a vegetação pode proporcionar efeitos negativos no inverno, reduzindo o aquecimento solar diurno. No entanto, em condições frias, a camada de vegetação também é responsável por diminuir a perda de calor da edificação durante a noite, aumentando a temperatura interna mínima. Assim, a parede verde representa uma alternativa eficiente para a melhoria do desempenho térmico da envoltória, principalmente em locais de clima quente, auxiliando no cumprimento dos critérios mínimos de desempenho térmico estabelecidos pela norma NBR 15.575 (ABNT, 2013). Sua eficácia decorre principalmente da proteção proporcionada à envoltória da edificação contra a incidência da radiação solar direta, além de envolver fenômenos complexos relacionados ao processo de evapotranspiração das plantas, que também influenciam na melhoria da qualidade do ar próximo à envoltória.

Embora as duas tipologias de paredes verdes apresentem comportamentos muito semelhantes, demonstrando o potencial de ambas na melhoria do desempenho térmico da envoltória e, consequentemente, da temperatura interna das edificações, nota-se um melhor desempenho térmico da tipologia de parede verde indireta, quando se utiliza o modelo HAMT, pela ação conjunta da umidade e da camada ventilada existente entre a vegetação e a envoltória.

Nas simulações computacionais horárias de desempenho térmico de edificações é usual não considerar a transferência de umidade na envoltória. Nessas análises, considera-se apenas o calor sensível. No entanto, como pode ser observado neste estudo, quando se utiliza o modelo HAMT do EnergyPlus há uma alteração considerável nos resultados que, conforme comparação com outros estudos, se mostram mais precisos.

Em vista disso, as paredes verdes podem representar uma solução bioclimática para novas construções, bem como para a instalação em construções já existentes. Em relação às habitações de interesse social, as paredes verdes podem melhorar seu desempenho térmico, uma vez que estas construções se destinam a uma população de baixa renda, que nem sempre pode pagar por decisões projetuais que elevem o consumo de energia destes edifícios, principalmente para o seu condicionamento quando este se faz necessário.

No que se refere à simulação do comportamento térmico de paredes verdes, criar um modelo computacional que reflita de maneira fiel todas as propriedades e aspectos relacionados às plantas ainda consiste em um grande desafio, seja pela falta de dados acerca das propriedades da vegetação ou pela não-consideração de aspectos importantes, como densidade e intensidade da folhagem, por parte do programa computacional. Estes aspectos reforçam a necessidade de novos estudos sobre o tema e o aprimoramento das ferramentas de simulação computacional. 


\section{Agradecimentos}

O presente trabalho foi realizado com apoio da Coordenação de Aperfeiçoamento de Pessoal de Nível Superior Brasil (CAPES) - Código de Financiamento 001. Agradecimentos também ao Programa de Pós-Graduação em Engenharia Civil (PROPEC) e à Universidade Federal de Ouro Preto.

\section{Referências}

ABNT - ASSOCIAÇÃO BRASILEIRA DE NORMAS TÉCNICAS. NBR 15.220: Desempenho térmico de edificações - 5 Partes. Rio de Janeiro, 2005. 92 p.

ABNT - ASSOCIAÇÃO BRASILEIRA DE NORMAS TÉCNICAS. NBR 15.575: Edifícios habitacionais - Desempenho. Rio de Janeiro, 2013. $381 \mathrm{p}$.

BARBOSA, M. C.; FONTES, M. S. G. de C. Jardins verticais: modelos e técnicas. PARC Pesquisa em Arquitetura e Construção, Campinas, SP, v. 7, n. 2, p. 114-124, jun. 2016. ISSN 1980-6809. Disponível em: http://periodicos.sbu.unicamp.br/ojs/index.php/ parc/article/view/8646304. Acesso em: 02 abr. 2019. DOI: https://doi.org/10.20396/parc.v7i2.8646304.

BESIR, A. B.; CUCE, E. Green roofs and green facades: a comprehensive review. Renewable and Sustainable Energy Reviews, v. 82, p. 915-939, 2018. DOI: http://dx.doi.org/10.1016/j.rser. 2017.09.106.

BRASIL. Lei 11.977, de 07 de julho de 2009. Dispõe sobre o Programa Minha Casa, Minha Vida. Diário Oficial da União, Brasília- DF.

BRÍGITTE, G. T. N. Integração de Desempenho na Avaliação de Projeto: modelo de informação e simulação computacional na etapa de concepção. Campinas, 2013. 225 f. Dissertação (Mestrado em Engenharia Civil) Faculdade de Engenharia Civil, Arquitetura e Urbanismo, Universidade Estadual de Campinas, Campinas, 2013.

CAETANO, F. D. N. Influência dos muros vivos sobre o desempenho térmico de edifícios. 2014. 117 f. Dissertação (Mestrado em Arquitetura, Tecnologia e Cidade) - Faculdade de Engenharia Civil, Arquitetura e Urbanismo, UNICAMP, Campinas, 2014.

CANTUÁRIA, G. A. C. Microclimatic impact of vegetation on building surfaces. Dissertation (Master's Degree) Environment and Energy Studies Programme. A. A. School of Architecture, London, 1995.

COSTA, C. S. Jardins verticais - uma oportunidade para nossas cidades? Vitruvius, Jun. 2011. Disponível em: http://www.vitruvius.com.br/revistas/read/arquitextos/12.133/3941. Acesso em: 4 mai. 2019.

CUCE, E. Thermal regulation impact of green walls: an experimental and numerical investigation. Applied Energy, v. 194, p. 247-254, 2016.

DAHANAYAKE, K. C.; CHOW, C. L. Comparing reduction of building cooling load through green roofs and green walls by EnergyPlus simulations. Building Simulation, v. 11, n. 3, p. 421-434, 2018.

DOE - U.S. DEPARTMENT OF ENERGY. EnergyPlus Version 9.0.1. Documentation: Engineering Reference. 2019.

EUMORFOPOLOU, E. A.; KONTOLEON, K. J. Experimental approach to the contribution of plant-covered walls to the thermal behaviour of building envelopes. Building and Environment, v. 44, n. 5, p. 1024-1038, 2009. DOI: https://doi.org/10.1016/j.buildenv. 2008.07.004.

GARRIDO, L. de. Sustainable architecture green in green. Edição Bilingual. Barcelona: Monsa, 2012.

HUNTER, A. M.; WILLIAMS, S. G. N.; RAYNER, J. P.; AYE, L.; HES, D.; LIVESLEY, S. J. Quantifying the thermal performance of green façades: a critical review. Ecological Engeneering, v. 63, p. 102-113, 2014. DOI: http://dx.doi.org/10.1016/j.ecoleng.2013.12.021. 
KÖHLER, M. Green Façades: a view back and some visions. Urban Ecosystems, London, v. 11, n. 4, p. 423-236. Spring Science + Business Media: 2008. ISSN 1573-1642. DOI: https://doi.org/10.1007/s11252-008-0063-X.

KONTOLEON, K. J.; EUMORFOPOULOU, E. A. The effect of the orientation and proportion of a plant- covered wall layer on the thermal performance of a building zone. Building and Environment, Elsevier, vol. 45, p. 1287-1303, 2010.

KOYAMA, T.; YOSHINAGA, M.; HAYASHI, H.; MAEDA, K.; YAMAUCHI, A. Identification of key plant traits contributing to the cooling effects of green façades using freestanding walls. Building and Environment, v. 66, p. 96-103, 2013. DOI: http://dx.doi.org/10.1016/j.buildenv.2013.04.020.

MANSO, M.; CASTRO-GOMES, J. Green wall systems: A review of their characteristics. Renewable and Sustainable Energy Reviews, v. 41, p. 863-871, 2015. DOI: http://dx.doi.org/10.1016/j.rser.2014.07.203.

MATHEUS, C.; CAETANO, F. D. N.; MORELLI, D. D. de O.; LABAKI, L. C. Desempenho térmico de envoltórias vegetadas em edificações no sudeste brasileiro. Ambiente Construído, Porto Alegre, RS, v. 16, n. 1, p. 71-81, jan./mar. 2016. ISSN 1678-8621 Associação Nacional de Tecnologia do Ambiente Construído.

DOI: http://dx.doi.org/10.1590/s167886212016000100061.

MONTANARI, K. B.; LABAKI, L. C. Comportamento térmico de ambientes internos sob a influência de envoltórias verdes. PARC Pesquisa em Arquitetura e Construção, Campinas, SP, v. 8, n. 3, p. 181-193, set. 2017. ISSN $1980-6809$. Disponível em: https://periodicos.sbu. unicamp.br/ojs/index.php/parc/article/view/8650241/17579. Acesso em: 07 abr. 2019. DOI: https://doi.org/10.20396/parc.v8i3.8650241.

MORELLI, D. D. de O. Desempenho de paredes verdes como estratégia bioclimática. 2016. 161 f. Tese (Doutorado em Arquitetura, Tecnologia e Cidade) - Faculdade de Engenharia Civil, Arquitetura e Urbanismo, UNICAMP, Campinas, SP, 2016.

MORELLI, D. D. de O.; LABAKI, L. C. Paredes verdes: estudo experimental sobre seus efeitos no espaço construído. In: ENCONTRO NACIONAL DE CONFORTO NO AMBIENTE CONSTRUÍDO E ENCONTRO LATINO AMERICANO DE CONFORTO NO AMBIENTE CONSTRUÍDO, 2013, Brasília. Anais [...]. Brasília: ENCAC/ELACAC, 2013. p. 1098-1107.

MUÑOZ, L. S.; CRUCIOL BARBOSA, M.; FONTES, M. S. G. de C; FARIA, J. R. G. Desempenho térmico de jardins verticais de tipologia fachada verde. PARC Pesquisa em Arquitetura e Construção, Campinas, SP, v. 10, p. e019013, mar. 2019. ISSN 1980-6809. Disponível em: https://periodicos.sbu.unicamp.br/ojs/index.php/parc/article/view/86 52775. Acesso em: 27 mar. 2019. DOI: https://doi.org/10.20396/parc.v10i0.8652775.

OTTELÉ, M. et al. Comparative life cycle analysis for green façades and living wall systems. Energy and Buildings, v. 43, n. 12, p. 3419-3429, dez. 2011.

OTELLÉ, M.; PERINI, K. Comparative experimental approach to investigate the thermal behavior of vertical greened façades of buildings. Ecological Engineering, v. 108, p. 152-161, 2017. DOI: http://dx.doi.org/10.1016/j.rser.2014.07.055.

PÉREZ, G.; COMA, J.; SOL, S.; CABEZA, L. F. Green Facade for energy savings in buildings: the influence of leaf area index and façade orientation on the shadow effect. Applied Energy, v. 187, p. 424-437, 2017. DOI: http://dx.doi.org/10.1016/j.apenergy.2016.11.055.

PÉREZ, G.; RINCÓN, L.; VILA, A.; GONZÁLEZ, J. M.; CABEZA, L. F. Behaviour of green facades in Mediterranean Continental climate. Energy Conservation and Management, v. 52, n. 4, p. 1861-1867, 2011. DOI: https://doi.org/10.1016/j.enconman.2010.11.008.

PERINI, K.; OTTELÉ, M.; FRAAIJ, A. L. A.; HAAS, E. M.; RAITERI, R. Vertical greening systems and the effect on air flow and temperature on the building envelope. Building and Environment, v. 46, p. 2287-2294, 2011. DOI: https://doi.org/10.1016/j.buildenv.2011.05.009.

PERINI, K.; OTTELÉ, M.; HAAS, E. M.; RAITERI, R. Vertical greening systems, a process tree for green façades and living walls. Urban Ecosystems, v. 16, n. 2, p. 265-277, 2013. DOI: https://doi.org/10.1007/s11252-012-0262-3. 
SÃO PAULO (Estado). Decreto $n^{\circ}$ 55.994, de 10 de março de 2015. Introduz alterações no artigo $4^{\circ}$ do Decreto $n^{\circ}$ 53.889, de 08 de maio de 2013, que regulamenta o termo de compromisso ambiental -TCA. Diário Oficial, São Paulo, SP, 11 de mar. de 2015.

SCHERER, M. J. Cortinas Verdes na arquitetura: desempenho no controle solar e na eficiência energética de edificações. 2014. 187 f. Tese (Doutorado em Arquitetura) - Universidade Federal do Rio Grande do Sul, Porto Alegre, RS, 2014.

SCHERER, M. J.; ALVES; T. S.; REDIN, J. Envoltórias vegetadas aplicadas nas edificações: benefícios e técnicas. Revista de Arquitetura IMED, Passo Fundo, vol. 7, n. 1, p. 84-101, Jan.-Jun., 2018 - ISSN 2318-110. DOI: https://doi.org/10.18256/2318-1109.2018.v711.2693.

SUSOROVA, I. Green facades and living walls: vertical vegetation as a construction material to reduce building cooling loads. In: PACHECO-TORGAL, F; LABRINHA, J. A.; CABEZA, L. F.; GRANQVIST, C.-G. (Org.). Eco-efficient materials for mitigating building cooling needs. Chicago: Elsevier, 2015. p.127-153.

DOI: http://dx.doi.org/10.1016/B978-1-78242380-5.00005-4.

VALESAN, M. Percepção ambiental de moradores de edificações com pele-verde em Porto Alegre. 2009. 180 f. Dissertação (Mestrado em Engenharia Civil) - Universidade Federal do Rio Grande do Sul, Escola de Engenharia, Porto Alegre, RS, 2009.

VALESAN, M.; FREDRIZZI, B.; SATTLER, M. A. Vantagens e desvantagens da utilização de peles-verdes em edificações residenciais em Porto Alegre segundo seus moradores. Ambiente Construído, Porto Alegre, v. 10, n. 3, p. 55-76, jul./set. 2010. ISSN 1678-8621.

WONG, I.; BALDWIN, A. N. Investigating the potential of applying vertical green walls to high-rise residential buildings for energy-saving in sub-tropical region. Building and Environment, v. 97, p. 34-39, 2016. DOI: http://dx.doi.org/10.1016/j.buildenv.2015.11.028.

WONG, N. H.; TAN, A. Y. K.; CHEN, Y.; SEKAR, K.; TAN, P. Y.; CHAN, D.; CHIANG, K.; WONG, N. C. Thermal evaluation of vertical greenery systems for building walls. Building and Environment, v. 45, n. 3, p. 663-672, 2010.

DOI: https://doi.org/10.1016/j.buildenv.2009.08.005.

WUFI. Release of WUFI 6.3.2. Disponível em: https://wufi.de/en/2019/04/16/release-wufi-pro-6-32/. Acesso em: 06 de ago. 2019.

YANG, F.; YUAN, F.; QIAN, F.; ZHUANG, Z.; YAO, J. Summertime thermal and energy performance of a double-skin green façade: a case study in Shanghai. Sustainable Cities and Society, v. 39, p. 43-51, 2018.

DOI: https://doi.org/10.1016/j.scs.2018.01.049.

YOSHIMI, J.; ALTAN, H. Thermal simulations on the effects of vegetated walls on indoor building enviroments. Proceedings of Building Simulation 2011: 12th Conference of International Building Performance Simulation Association, Sydney, 14-16 November.

\title{
${ }^{1}$ Luana Resende de Sousa
}

Arquiteta e Urbanista, mestranda do Programa de Pós-Graduação em Engenharia Civil. Universidade Federal de Ouro Preto. Endereço postal: Campus Universitário, Morro do Cruzeiro, Ouro Preto, MG, Brasil, CEP 35400-000

\author{
${ }^{2}$ Henor Artur de Souza \\ Engenheiro Mecânico. Doutor. Programa de Pós-Graduação em Engenharia Civil. Universidade Federal de Ouro \\ Preto. Endereço postal: Campus Universitário, Morro do Cruzeiro, Ouro Preto, MG, Brasil, CEP 35400-000
}

\section{${ }_{3}^{3}$ Adriano Pinto Gomes}

Arquiteto e Urbanista. Doutor. Instituto Federal de Minas Gerais, Campos Ouro Preto. Endereço postal: Rua Pandiá Calógeras, 898, Bairro Bauxita, Ouro Preto, MG, Brasil, CEP 35400-000 